REVISTA DE DERECHO UNED, NÚM. 9, 2011

\title{
CONTENIDO Y LÍMITES DE LA LIBERTAD DE CÁTEDRA EN LA ENSEÑANZA PÚBLICA NO UNIVERSITARIA
}

\author{
Roberto Suárez MaLAGÓN \\ DEA. Doctorando del Departamento de Derecho Político de la UNED \\ Profesor de Enseñanza Secundaria, especialidad Formación y \\ Orientación Laboral
}

Resumen: Desde su reconocimiento en el artículo 20.1 c) de la Constitución la posibilidad de extensión a los niveles no universitarios del derecho fundamental a libertad de cátedra ha dado lugar a diversos enfoques doctrinales desarrollados a la luz de la esencial sentencia del Tribunal Constitucional 5/1981, de 13 de febrero. En el presente artículo se pretenden aportar argumentos jurídicos, jurisprudenciales y de práctica docente para aclarar el grado de aplicación de esta libertad en el concreto ámbito de la enseñanza pública no universitaria, con especial incidencia en sus niveles no obligatorios, aquellos en los que la edad, madurez y preparación de los alumnos los sitúan de facto en un campo más cercano a la etapa universitaria. Para ello se han desarrollado de manera complementaria dos líneas metodológicas de trabajo centradas en el análisis del contenido y los límites de este derecho fundamental. Por un lado se confrontan las principales posturas defendidas por la doctrina al respecto y, complementariamente, se analizan las funciones propias de la labor docente en estas enseñanzas, las previsiones normativas asentadas en la legislación educativa así como la interpretación desarrollada por la escasa jurisprudencia en esta concreta materia.

Palabras clave: educación, libertad de cátedra, enseñanza pública no universitaria, contenido esencial, contenido positivo y negativo, límites específicos. 
Abstract: Since its recognition in the article $20.1 \mathrm{c}$ ) of the Spanish Constitution, the possibility of extending the fundamental right of academic freedom to no university levels has provoked several doctrinal approaches that were developed under the essential judgement of the Constitutional Court 5/1981, February $13^{\text {th }}$. In this article, we try to contribute with some legal, jurisprudential and teaching methodology in order to clarify the extent that this freedom is applied to in the sphere of the no university state teaching, especially in those levels that are not compulsory, when the age of the students, their maturity and their training places them very close to the university stage. In this way, two methodological working lines, which have been focused in the analysis of the content and the boundaries of this fundamental right, have been developed. On the one hand, the main stances defended by the doctrine on this matter and, additional, the normative predictions established in the educational legislation as well as the interpretation that has been developed by the scarce legislation in this specific subject.

Key words: education, academic freedom, no university state teaching, essential content, positive and negative content, specific limits.

Sumario: I. Introducción.-II. Contenido de la libertad de cátedra.-II.1. Las funciones propias de la labor docente.-II.2. El doble contenido del derecho a la libertad de cátedra: contenido negativo y positivo.-II.2.A. El contenido negativo de la libertad de cátedra.-II.2.B. El contenido positivo de la libertad de cátedra.-II.3. Delimitación del contenido esencial o mínimo de esta libertad.-III. Límites específicos al ejercicio de esta libertad.-III.1. El rigor científico y la ausencia de adoctrinamiento o de proselitismo en el centro docente.-III.2. La libertad de conciencia de los alumnos.-III.3. Las normas de organización de la docencia y del centro.-III.4. La programación de la disciplina a impartir.-III.5. El deber de enseñar.-III.6. El artículo 27.2 referido al objeto de la educación.-III.7. La lealtad del docente a la Constitución.-III.8. La libertad del estudio del alumno como límite a la libertad de cátedra.-III.9. El principio de neutralidad ideológica de la enseñanza pública no universitaria.-III.10. El derecho a la objeción de conciencia a contenidos curriculares. Libertad de cátedra y contenido de las asignaturas.-IV. Conclusiones.

\section{INTRODUCCIÓN}

El derecho fundamental a la libertad de cátedra aparece reconocido en el artículo 20.1 c) de la Constitución con la austera literalidad 
de «se reconoce y protege el derecho a la libertad de cátedra». El mismo ha sido posteriormente definido por nuestro Alto Tribunal como la «posibilidad de expresar las ideas o convicciones que cada profesor asume como propias en relación a la materia objeto de su enseñanza» ${ }^{1}$. Por otro lado, la posibilidad de extensión de la libertad de cátedra a los niveles educativos no universitarios ha sido controvertida y objeto de amplia confrontación doctrinal y polémica parlamentaria ${ }^{2}$, considerando además que, en palabras de FERnÁndEZ-

1 Sentencia 217/1992, de 1 de diciembre, FJ $2^{\circ}$.

2 Por señalar sólo algunos ejemplos de debates parlamentarios, que pueden servir de perfecta introducción al carácter cuando menos polémico del objeto del presente estudio, partimos aquí de la postura de MARTí Sánchez J. M., «Factor religioso y enseñanza en España», Anuario de Derecho Eclesiástico del Estado, núm.16, 2000, pág. 464. Refiriéndose a los debates parlamentarios del proceso constituyente recuerda que todas «las propuestas de cambiar la denominación de la libertad de cátedra respondían al objetivo de ampliar el alcance de esta libertad a todos los docentes». Precisamente como meridiano ejemplo de las citadas propuestas encontramos tal y como aparece en el compendio Constitución Española, trabajos parlamentarios, vol. 2, pág. 2079, el debate del Pleno del Congreso de los Diputados con ocasión de la enmienda presentada por el grupo parlamentario Comunista orientada a sustituir la expresión libertad de cátedra por la de libertad docente. El Diputado FraGA IRIBARNE en nombre del Grupo Parlamentario de Alianza Popular defendía que existe «una diferencia fundamental entre la libertad de cátedra, como tradicionalmente se entiende, como el derecho en instituciones de investigación y Enseñanza Superior del profesor de enseñar libremente, y también del alumno de escoger libremente los programas y los profesores, que evidentemente no es lo mismo que reconocer a un profesor de primaria, de EGB, con alumnos de muy escasa edad, en un colegio, que pretenda...el improvisar de pronto allí sobre las cuestiones filosóficas o dar lecciones prácticas de sexualidad a los alumnos». En esta etapa de primaria afirmaba este Diputado que «entiendo que, con arreglo al viejo principio de que el niño merece un respeto especial, ahí el concepto de libertad de cátedra no es aplicable». Por el contrario la Diputada BRABo CASTELLS, en representación del Grupo Parlamentario Comunista expuso que «la docencia es una actividad, como todo el mundo sabe, profesional y científica, y ni como profesional ni mucho menos como investigador y científico es posible negar al docente la libertad de expresión». Posteriormente, ya una vez en vigor nuestra Carta Magna, vuelve a entrar en juego el asunto de la extensión de la libertad de cátedra con ocasión de los debates originados en torno al artículo 15 del proyecto de la Ley Orgánica del Estatuto de Centros Escolares. En este momento histórico, recogiendo lo que aparece en el Diario de Sesiones del Congreso de los Diputados, núm. 72, de 11 de marzo de 1980, pág. 4.822, Alzaga VillaAmil, afirmaba que en el sistema educativo previsto en nuestra Constitución y con respecto a los centros docentes públicos «no hay el menor problema respecto a la libertad de cátedra», si bien matizaba que «no hay al menos otro problema que el del nivel del alumnado, dimanante de la edad del alumno». Continuaba su argumentación afirmando que la auténtica, genuina y absoluta libertad de cátedra se desarrolla en la Universidad con adultos, de modo que, en su opinión, «a menor edad menor libertad de cátedra, porque hay que respetar la infancia y la juventud». En este sentido añade que «incluso en el menor nivel, en puridad, no hay cátedra» y concluye que «nunca se ha hablado en la escuela de cátedra». 
Miranda, «nos encontramos ante uno de los preceptos constitucionales de interpretación más polémica y que resulta difícil ubicar sistemáticamente» ${ }^{3}$. El presente estudio trata de aportar argumentos, a partir del análisis del contenido y los límites específicos de este derecho fundamental así como de las líneas doctrinales seguidas al respecto, para la defensa de la aplicación de la libertad de cátedra en el ámbito de la enseñanza pública no universitaria. Y todo ello partiendo del hecho de que su aplicación a la educación en etapas no universitarias ha sido tempranamente acogida en una interpretación de nuestro Tribunal Constitucional en la que se sentaron las bases de la extensión de este derecho fundamental a cualquier ámbito educativo ${ }^{4}$.

\section{CONTENIDO DE LA LIBERTAD DE CÁTEDRA}

\section{II.1. Las funciones propias de la labor docente}

El contenido de la libertad de cátedra no aparece desarrollado o al menos perfilado en nuestro texto Constitucional, el cuál se refiere a este derecho como nuda libertad, es decir, sin mención, descripción o

${ }^{3}$ Fernández-Miranda y Campoamor, A., y García Sanz, R. M., «Artículo 20. Libertad de expresión y derecho a la información», en Comentarios a la Constitución Española de 1978, tomo II, dir. por Alzaga Villaamil, Madrid: Edersa, 1997, pág. 548.

${ }^{4}$ Precisamente comparando el contenido y alcance de la libertad de cátedra entre el modelo español y el antecedente histórico alemán, el Tribunal Constitucional reconocía en la Sentencia 5/1981, de 13 de febrero, en su Fundamento Jurídico $9^{\circ}$ que «aunque tradicionalmente por libertad de cátedra se ha entendido una libertad propia sólo de los docentes en la enseñanza superior o, quizás más precisamente, de los titulares de puestos docentes denominados precisamente cátedras y todavía hoy en la doctrina alemana se entiende, en un sentido análogo, que tal libertad es predicable sólo respecto de aquellos profesores cuya docencia es proyección de la propia labor investigadora, resulta evidente, a la vista de los debates parlamentarios, que son un importante elemento de interpretación, aunque no la determinen, que el constituyente de 1978 ha querido atribuir esta libertad a todos los docentes, sea cual fuere el nivel de enseñanza en el que actúan y la relación que media entre su docencia y su propia labor investigadora». Hemos de recordar, siguiendo a GARRIDO FALLA, F., en Comentarios a la Constitución, Madrid: Civitas, 2001, pág. 645, que «la doctrina que contiene esta sentencia representa la más autorizada interpretación del artículo 27 de nuestra Constitución» En todo caso, esta línea interpretativa ha sido matizada con posterioridad en otras sentencias fundamentales para la adecuada comprensión de este derecho como la STC 179/1996, de 12 de noviembre se deriva que esta libertad estará condicionada por los planes de estudio, de manera que en los niveles inferiores en que la concreción dichos planes es mayor, lógicamente la libertad del enseñante disminuirá. 
desarrollo de las facultades positivas que implica ${ }^{5}$. Por ello resulta evidente que esta desnudez en el significado de este derecho ha generado discrepancias a la hora de fijar su titularidad y sobre todo a la hora de precisar su contenido y especificar los propios límites del mismo. En cuanto a los sujetos de este derecho, nos inclinamos por aceptar su extensión a todo el personal docente, lo cuál significa que todos ellos se encuentran incluidos dentro del ámbito de protección del artículo 20.1.c). Ahora bien esta titularidad amplia no implica que el contenido de este derecho fundamental sea igual para todos los puestos docentes ${ }^{6}$.

A partir de estas premisas, resultaría conveniente desarrollar brevemente cuáles son las funciones propias de la labor docente, con el objetivo de comprobar si las mismas se encuentran presentes tanto en los niveles inferiores de la enseñanza como en el nivel universitario. Se trata de analizar cuáles son los puntos comunes y diferentes en el proceso de enseñanza-aprendizaje propio de estos dos niveles educativos, acudiendo para ello al análisis de indicadores como la transmisión de conocimientos, la valoración, la crítica, la investigación, la metodología y también cuál es el sujeto receptor de los mensajes educativos. Esta claro que tanto en la enseñanza superior como en toda la educación no universitaria se encuentra presente la etapa de transmisión de conocimientos científicos y de preparación de esos mensajes a transmitir ${ }^{7}$. Sin embargo, puede resultarnos más difícil reconocer que la etapa de creación de los contenidos que formarán parte del mensaje a enseñar a los alumnos, se pueda predicar de todos los niveles educativos y no solamente de los universitarios. En este sentido se puede afirmar que si bien ambas etapas encierran una transmisión de conocimientos científicos, la enseñanza que se desarrolla en la etapa no universitaria tendría «un carácter básicamen-

${ }^{5}$ CRemades, J., «La libertad de cátedra en el ordenamiento jurídico español», Estado e Dereitto, núm. 11,1993, pág. 26.

${ }^{6} \mathrm{Y}$ es que el problema no se resuelve con una simple descripción de los sujetos o titulares de esta libertad sino que, abundando en sus raíces, la cuestión es cómo resolver los posibles conflictos de derechos. Para ello resultará fundamental determinar el contenido esencial de este derecho partiendo de la premisa de que no se trata de un contenido uniforme, sino gradual, que, con matices, ira disminuyendo según se descienda en el nivel educativo. Esta es la base de la que parte la jurisprudencia constitucional asentada en la Sentencia 5/1981 y posteriormente aclarada, en referencia al nivel universitario, por la STC 217/1992, de 1 de diciembre.

7 Se trata de dos etapas que siempre se reconocen y aceptan en toda labor educativa puesto que la creación del mensaje en cuanto tal y su transmisión constituyen la razón de ser de toda labor educativa, con independencia del nivel en el cuál se inserte. Castillo CóRdova, L., Libertad de cátedra en una relación laboral con ideario, Valencia: Tirant lo Blanch, 2006, pág. 324. 
te informativo en cuanto que los conocimientos se presentan como verdades apodícticas, avaladas por general aceptación en la comunidad científica ${ }^{8}$. Así en los niveles educativos inferiores la enseñanza se orienta esencialmente a proporcionar a los alumnos un conjunto de conocimientos básicos que se consideran adecuados a cada estadio formativo. Y eso se deberá hacer de una manera más o menos uniforme, con un contenido subordinado a las reglamentaciones de planes de estudio. Por el contrario se puede considerar que la enseñanza universitaria es principalmente crítica y valorativa ${ }^{9}$, con un contenido amplio presentado sobre la base de mayor libertad metodológica y valorativa del mismo.

Pero caben, en todo caso, diversas aclaraciones a estas aparentes diferencias entre ambos niveles educativos. Los matices que a continuación se aportan pueden servir para introducir una de las ideas fuerza del presente artículo como es la del mayor peso de la libertad de cátedra en la actual enseñanza no universitaria, especialmente en aquellos niveles de estas etapas educativas encajados en la denominada enseñanza posobligatoria ${ }^{10}$. Es en esta etapa no obligatoria en la que de forma progresiva y conforme aumenta la edad de los alumnos, la especialización de los aprendizajes y los itinerarios académicos se acercan más a la integración en el mercado de trabajo, se puede considerar que la enseñanza puede ir también adquiriendo ese carácter crítico y valorativo. Y ello porque, al menos por afinidad, nos encontramos con rangos de edad y madurez más próximos a la Universidad en los que la capacidad de discernimiento del alumnado va siendo cada vez mayor. Así lo ha reconocido nuestro Tribunal Constitucional al afirmar, en su Sentencia 5/1981, de 13 de febrero, FJ. 13, que la amplitud de la libertad que cada profesor puede ejercer dependerá en gran medida del grado de madurez personal de los destinatarios de la enseñanza y el nivel científico de los conocimien-

8 Begué Cantón, G., «La libertad de enseñanza», en VVAA, XII Jornadas de Estudio. Los derechos fundamentales y libertades públicas, vol. II, Madrid: Ministerio de Justicia, 1992, pág. 1219.

9 En este sentido RODRíGUEz COARASA considera un exceso el realzar al máximo la importancia de este carácter crítico y valorativo, afirmando que «la mera transmisión de saberes sin valoración crítica no es estrictamente enseñanza universitaria». RodRíGuez Coarasa, C., La libertad de enseñanza en España, Madrid: Tecnos, 1998, pág. 214.

10 Edades posteriores a los 16 años, edad hasta la cuál se articula la enseñanza obligatoria para todo ciudadano. Aquí se sitúan el Bachillerato (acceso para alumnos que hayan superado la Enseñanza Secundaria Obligatoria), la Formación Profesional articulada en ciclos formativos de grado medio (acceso para alumnos que hayan superado la ESO) o de grado superior (acceso quienes hayan superado el Bachillerato), Estudios Artísticos, Enseñanzas de Idiomas en las Escuelas Oficiales de Idiomas...etc. 
tos que a ellos se han de transmitir, siendo esta una "amplitud muy variable en relación con quienes enseñen en los centros escolares regulados por la Ley Orgánica 5/1980, ya que en ellos se comprenden desde los más elementales niveles de enseñanza, hasta los cursos de Bachillerato y de Orientación Universitaria, más cercanos ya a la enseñanza universitaria, tanto porque en parte (el COU) sirven de preparación para ella, como porque con frecuencia los alumnos de BUP y de COU han superado el tope constitucional de la mayoría de edad (artículo $12 \mathrm{CE}$ )».

Otro argumento a considerar para la defensa de que esa etapa de creación de los contenidos, con su componente de investigación, se desarrolla también en la educación no universitaria, lo encontramos en la propia normativa educativa. Empezando por nuestra Norma Fundamental, recordamos ahora su artículo 20.1.b en el que se reconoce y protege, sin limitación en su titularidad, el derecho a «la producción y creación literaria, artística, científica y técnica». Y ya en el ámbito del legislador orgánico, nos encontramos con múltiples apoyos a nuestra tesis en la actual Ley Orgánica 2/2006, de 3 de mayo, de Educación. Así en el apartado n) de su artículo primero se establece que el sistema educativo español tiene como uno de sus principios «el fomento y la promoción de la investigación, la experimentación y la innovación educativa». Igualmente en su artículo 90 se defiende la importancia del reconocimiento de «la labor didáctica o de investigación de profesores y centros, facilitando la difusión entre los distintos centros escolares de los trabajos o experiencias». En la misma línea, en su artículo 91.1 se fija como una de las funciones del profesorado «la investigación, la experimentación y la mejora continua de los procesos de enseñanza correspondiente».

Por último, de nuevo encontramos en los pronunciamientos del propio Tribunal Constitucional argumentos favorables a esta tesis de que la investigación y al carácter crítico y valorativo de la labor docente tiene también su peso específico en las últimas etapas de la enseñanza no universitaria. Así se puede considerar que el Juez de la Constitución ha realizado un reconocimiento implícito de estas funciones de investigación y estudio en los niveles no universitarios al entender que «esta dimensión personal de la libertad de cátedra, configurada como derecho de cada docente, presupone y precisa, no obstante, de una organización de la docencia y de la investigación que la haga posible y la garantice» ${ }^{11}$. A partir de estos pronunciamientos del Tribunal Constitucional si todos los docentes tienen atribuida la

\footnotetext{
11 Sentencia 217/1992, de 1 de diciembre, fundamento jurídico $2^{\circ}$.
} 
libertad de cátedra y ésta exige una determinada organización de la investigación y la docencia, entonces se puede llegar a la conclusión del reconocimiento a todos los profesores de esa función de investigación (de docencia) ${ }^{12}$. Por último, en la Sentencia 5/1981 se afirma que «la libertad de cátedra es, en este sentido, noción incompatible con la existencia de una ciencia o una doctrina oficiales ${ }^{13}$, de modo que todo docente tiene la posibilidad de participar en la creación y formulación de la ciencia -ciencia oficial- y la ideología -entendida como doctrina oficial- ${ }^{14}$.

Por tanto podemos concluir este análisis de las funciones propias de la labor docente afirmando que la investigación y el aporte valorativo y crítico de los conocimientos que de ella se deriva se encuentra también en la enseñanza no universitaria sin que ello implique el que su alcance y contenido sea plenamente asimilable con esa misma función docente en la Universidad. Pero, ¿̇en qué consisten las diferencias entre estas dos etapas?. Lo cierto es que en la etapa no universitaria existe en un primer nivel un entramado de enseñanzas mínimas y de currículos predeterminados que perfilan las asignaturas a impartir y su metodología. Y en un segundo nivel, ya en los propios centros con autonomía pedagógica legalmente reconocida, la labor docente se ajusta aún más por la vía de mecanismos de planificación docente como son los Proyectos Educativos de Centro, Proyectos Curriculares de Etapa o las programaciones didácticas. Dicho esto deseamos apuntar una consecuencia lógica y de doble interpretación derivada de la existencia de ese entramado de enseñanzas mínimas y generales: por una parte, es cierto que con ello se unifica y limita la diversidad creativa e investigadora del profesorado, esto es, su aportación personal. Pero por otra parte, dado su carácter general, resulta obvio que deben ser concretadas a la realidad docente de cada grupo de alumnos por lo que tienen un alto índice de flexibilidad que obliga al docente no universitario a una labor investigadora y creativa de conocimientos adaptados ${ }^{15}$. Así se puede defender que el do-

12 Castillo Córdova, L., Libertad de cátedra en una relación laboral con ideario, cit. en núm. 7, pág. 325. En la misma línea se han postulado también DE EsTEBAN, J., GoNZalez-Trevijano, P. J., Curso de Derecho Constitucional Español II, Madrid: Servicio de Publicaciones de la Facultad de Derecho, Universidad Complutense de Madrid, 1993, pág. 140.

13 Sentencia 5/81, de 13 de febrero, FJ $9^{\circ}$.

14 A favor de esta máxima de incluir la etapa de creación en la labor de los docentes no universitarios se ha manifestado, además del citado CASTILlo CóRDOVA, VIDAL PRADo, C., «Libertad de cátedra en los centros docentes de iniciativa social», Revista Vasca de Administración Pública, vol. 50,1998, pág. 266.

15 Apoyando esta reflexión, Salguero afirma que desde este enfoque teórico-con- 
cente no universitario aporta, a la información objetiva de los distintos conocimientos científicos o técnicos que está predeterminada por los mínimos señalados, un elemento subjetivo consistente en su enfoque de aportaciones personales y juicios de valor derivados de sus experiencias y formación personalizada y derivadas, en fin, de actividades de estudio e investigación. Concluimos entonces que la función de investigación y aportación personal del docente de etapas inferiores se encuentra, por una parte, claramente minorada y mediatizada respecto al mayor espectro de libertad individual de un docente universitario. Pero, por otra parte, esos límites y corsés unificadores no suponen en ningún caso su anulación o inexistencia y menos aún en las etapas educativas no obligatorias, con alumnado mayor de edad, con madurez personal y en muchos casos profesional y con programas académicos más abiertos.

\section{II.2. El doble contenido del derecho a la libertad de cátedra: contenido negativo y positivo}

Nos encontramos ante una libertad que comprende las tres manifestaciones paradigmáticas de la libertad jurídica: en su aspecto puramente negativo, la ausencia de constricciones; en su aspecto positivo estricto, la autonomía y participación; y en su aspecto positivo potencial, las facultades de hacer ${ }^{16}$. Más concretamente y siguiendo lo establecido por nuestro Alto Tribunal, en la jurisprudencia que a continuación citaremos, esta libertad se articula con un doble contenido: un contenido de inmunidad o negativo y un conjunto de facultades de acción o contenido positivo.

\section{II.2.A. El contenido negativo de la libertad de cátedra}

Primeramente se habla de un contenido negativo común o uniforme definible como el derecho a resistirse contra cualquier mandato oficial de dar a su enseñanza una orientación ideológica deter-

ceptual encuentra explicación la reiterada preocupación por mostrar el carácter amplio, abierto, flexible y descentralizado del currículo en el que caben diversas formas de adaptación y realización. Esta textura abierta permite colegir que consiste en un conjunto de propuestas de acción o de hipótesis que el profesorado puede revisar y actualizar. Salguero Salguero, M., Libertad de Cátedra y Derechos de los Centros Educativos, Barcelona: Ed. Ariel, 1997, págs. 127-128.

${ }^{16}$ Gálvez Montes, J., «Comentario al artículo 20 de la Constitución», en VV.AA., Comentarios a la Constitución, Madrid: Civitas, 2001, pág. 463. 
minada. En palabras del Alto Tribunal este contenido negativo uniforme capacitará al profesor "para resistir cualquier mandato de dar a su enseñanza una orientación ideológica determinada; es decir, cualquier orientación que implique un determinado enfoque de la realidad natural, histórica o social dentro de lo que el amplio marco de los principios constitucionales hace posible. Libertad de cátedra es, en ese sentido, noción incompatible con la existencia de una ciencia o una doctrina oficiales ${ }^{17}$. Por lo tanto esta libertad consistirá «en la posibilidad de expresar las ideas o convicciones que cada profesor asume como propias en relación a la materia objeto de su enseñanza, presentando de este modo un contenido, no exclusivamente pero sí predominantemente negativo ${ }^{18}$.

Pero además de prohibir estos condicionamientos ideológicos de los docentes, dentro de este contenido negativo se perfila una exigencia adicional derivada del principio de libre transmisión del saber. Libertad de cátedra supone entonces autonomía en lo que se refiere a los contenidos de la investigación y la enseñanza. Implica libertad para «elegir, utilizar y aplicar los métodos, procedimientos y tratamientos conducentes a la adquisición, exposición y transmisión de los conocimientos científicos» ${ }^{19}$.

\section{II.2.B. El contenido positivo de la libertad de cátedra}

Nuestro Tribunal Constitucional ha reconocido también, aunque con un contorno más impreciso, un contenido positivo de la libertad de cátedra. No define directa y expresamente lo que se ha de entender por tal contenido positivo, sino que dibuja sus perfiles estableciendo una serie de pautas a partir de las cuáles se han de ir intuyendo las facultades concretas que lo integran. Así el Alto Tribunal afirma que en los niveles superiores se tratará de un amplio contenido mientras que, por el contrario, en los niveles inferiores «y de modo en alguna medida gradual, este contenido positivo de la libertad de enseñanza va disminuyendo» ${ }^{20}$.

17 Sentencia $5 / 81$, de 13 de febrero, FJ $9^{\circ}$, párrafo $4^{\circ}$.

18 Sentencia 217/1992, de 1 de diciembre, fundamento jurídico $2^{\circ}$.

${ }^{19}$ Lorenzo Vázouez, P., Libertad religiosa y enseñanza de la Constitución, Madrid: Centro de Estudios Políticos y Constitucionales, pág. 159. También se refiere a esta extensión del contenido negativo Castillo Córdova destacando su importancia «a pesar de no haber sido puesta de manifiesto expresamente por el Tribunal Constitucional». CASTILlo CóRdOVA, L., Libertad de cátedra en una relación laboral con ideario, cit. en núm. 7 , pág. 330 .

${ }^{20}$ Sentencia 5/81, de 13 de febrero, FJ $9^{\circ}$. Como se observa el Tribunal Constitu- 
Ante esta falta de definición expresa por parte del Juez de la Constitución, CASTILLO CORDOVA ${ }^{21}$ ha interpretado que las facultades de hacer que conlleva este contenido positivo de la libertad de cátedra son las indispensables para el desarrollo de toda la labor docente. Esto es, todas las facultades referidas tanto a la libre creación y transmisión de mensajes educativos como a la libre determinación del método de transmisión de los mensajes ${ }^{22}$. En esta línea SALVADOR afirma que desde el punto de vista positivo esta libertad «ampara la libre programación y el desarrollo igualmente libre de la docencia, si bien respetando los planes y programas mínimos establecidos por quienes tienen competencia para ello» ${ }^{23}$. Por su parte SALGUERo considera que, en su vertiente positiva, la libertad de cátedra «es una beligerancia intelectual no dogmática, sustentada en el valor de la tolerancia, en el respeto a la dignidad y libre desarrollo de la personalidad, sujeta a las exigencias de la verdad científica e inmune a una ciencia o doctrina oficial» ${ }^{24}$.

Pero además, a diferencia del contenido negativo, ahora nos encontramos con un contenido no uniforme sino variable en función de los condicionantes y características propias de cada puesto docente. Se trata de la antes comentada modulación determinada por la acción combinada de dos factores: la naturaleza pública o privada y el nivel o grado educativo al que tal puesto docente corresponde. Así en los niveles de enseñanza no universitaria el alcance de las facultades que rodean a este contenido positivo será bastante limitado ${ }^{25}$ habida

cional utiliza textualmente aquí y de manera que puede inducir a error la expresión libertad de enseñanza pero, más precisamente, se debe entender que en realidad se refiere a la libertad de cátedra. Y ello porque es a esta libertad es a la que se esta refiriendo en este fundamento jurídico al establecerle un doble ámbito de significación, positivo y negativo.

${ }^{21}$ Castillo CóRdova, L., Libertad de cátedra en una relación laboral con ideario, cit. en núm. 7, pág. 331. En igual línea ExPósito, E., La libertad de cátedra, Madrid: Editorial Tecnos, 1995, págs. 159-160.

${ }^{22}$ Por tanto el contenido positivo de la libertad de cátedra significa también libertad de elección del método pedagógico por parte del docente, la cuál variará de modo decreciente desde el nivel universitario hasta el nivel primario. Existe así un ámbito de libertad de todo docente constituido por una serie de cualidades o características expositivas o pedagógicas que diferencian a unos docentes de otros, que definen un modo personal de llevar a la práctica del aula los currículos y programas.

23 Salvador Martínez, M., "Los derechos de la educación», en SÁNCHEZ GONZÁLEZ S. (coord.), Dogmática y práctica de los derechos fundamentales, Valencia: Tirant lo Blanch, 2006, pág. 403.

${ }^{24}$ Salguero Salguero, M., "Libertad de Enseñanza, neutralidad y libertad de cátedra como formas de pluralismo institucionalizado", Derechos y Libertades: Revista del Instituto Bartolomé de las Casas, núm. 5,1995, pág. 552.

${ }^{25}$ En palabras del Alto Tribunal, en estos niveles inferiores, «de una parte, son los 
cuenta de que en ese puesto concreto la labor docente está condicionada por las enseñanzas mínimas y las directrices pedagógicas concretadas en diferentes etapas sucesivas hasta llegar a la programación didáctica de cada asignatura elaborada ya por cada profesor. Y ello teniendo en cuenta que, en teoría al menos, estos condicionamientos y limitaciones no deberían ser motivos para alegar vulneración de la libertad de cátedra si existe una adecuada autonomía y participación de todos los docentes en la redacción y aprobación de los diferentes currículos, programaciones y proyectos que conforman el entramado pedagógico no universitario ${ }^{26}$. Pero como señala ExPósito esta modulación no incide en la adopción, por parte del docente «de una determinada manera de ejercer o desarrollar el contenido de sus explicaciones, pues (...) reconocer que el docente tiene libertad para ejercer docencia lleva implícito la forma en que ésta ha de transmitirse, es decir, el método de explicaciones que siga en el ejercicio de la docencia $»^{27}$.

\section{II.3. Delimitación del contenido esencial o «mínimo» de la libertad de cátedra}

Siguiendo lo establecido en la jurisprudencia de nuestro Tribunal Constitucional ${ }^{28}$ sobre este concepto, recordamos ahora que el con-

planes de estudios elaborados por la autoridad competente, y no el propio profesor, los que determinan cuál haya de ser el contenido mínimo de la enseñanza y son también estas autoridades las que establecen cuál es el elenco de medios pedagógicos entre los que puede optar el profesor (artículo 27.5 y $8 \mathrm{CE}$ ) y, de la otra y sobre todo, éste no puede orientar ideológicamente su enseñanza con entera libertad de manera que juzgue más conforme a sus convicciones». Sentencia 5/81, de 13 de febrero, FJ $9^{\circ}$, párrafo 5.

${ }_{26}$ Por el contrario, en el nivel educativo universitario y por contraposición a lo dispuesto por el Tribunal Constitucional para los niveles no universitarios, Salguero afirma que se podría deducir que este amplio contenido positivo implica que el profesor no universitario no tendrá que elegir entre ningún elenco de medios pedagógicos y podrá dar a su enseñanza la orientación ideológica que considere más conforme a sus convicciones con entera libertad. Salguero Salguero, M., Libertad de Cátedra y Derechos de los Centros Educativos, cit. en núm. 15, pág. 82. Ahora bien esto no deberá suponer total libertad puesto que existirán para todo profesor unas mínimas limitaciones derivadas del poder público al que se le atribuye la programación general de la enseñanza (art. 27.5 CE) o la regulación de las condiciones de obtención, expedición y homologación de los títulos académicos y profesionales (art. 149.1.30 CE) y también limitaciones internas de cada universidad derivadas de sus estatutos o del ideario.

27 Expósito, E., La libertad de cátedra, cit. en núm. 21, págs. 167-168.

${ }_{28}$ La sentencia clave al efecto es la Sentencia 11/81, de 8 de abril, según la cuál el núcleo esencial es «aquella parte del contenido de un derecho sin el cual éste pierde su peculiaridad, de modo que es ineludiblemente necesario para que el derecho permita 
tenido esencial de un derecho fundamental estará constituido por «aquellas facultades o posibilidades de actuación necesarias para que el derecho sea reconocible como pertinente al tipo descrito ${ }^{29}$. De este modo, si no existen dichas facultades, no estaremos ante ese concreto derecho fundamental, sino que se producirá una desnaturalización del mismo. En el ámbito doctrinal existen múltiples referencias a la determinación de este contenido esencial en el caso de la libertad de cátedra. Resumidamente ${ }^{30}$ se podría afirmar que para la misma el contenido esencial o mínimo básico de este derecho consiste en dos facultades. La primera sería el no someterse a ideas científicas impuestas, a orientaciones que impliquen un determinado enfoque de la realidad natural, histórica o social y a imposiciones que deriven de una ciencia social. La segunda supone la posibilidad de expresar libremente las ideas, las convicciones científicas racionalmente asumidas por el profesor en relación con una disciplina en el momento de la investigación; en la transmisión de esos conocimientos; en la elección del método más adecuado. Sirva de ejemplo de la visión doctrinal general la definición realizada por SALGUERO para quién este contenido esencial o mínimo básico consistiría en «no someterse a ideas científicas impuestas, a orientaciones que impliquen un determinado enfoque de la realidad natural o social y a imposiciones que deriven de una ciencia oficial. También forma parte del contenido esencial -desde una vertiente positiva- la posibilidad de expresar libremente ideas y convicciones científicas racionalmente asumidas por el profesor en relación con una disciplina académica, en el

a su titular la satisfacción de aquellos intereses para cuya consecución el derecho le otorga». Esta sentencia ha sido reiterada en su línea argumental en la Sentencia 37/1987, de 26 de marzo y en la Sentencia 196/1987, de 11 de diciembre, Fundamento Jurídico $5^{\circ}$ y $6^{\circ}$.

${ }^{29}$ Parejo Alfonso, L., «El contenido esencial de los derechos fundamentales en la jurisprudencia constitucional a propósito de la Sentencia del Tribunal Constitucional de 8 de abril de 1981 », Revista Española de Derecho Constitucional, núm. 3, 1981, pág. 187.

${ }^{30} \mathrm{Y}$ es que en esta postura resumida coinciden, en líneas generales, diversos autores como Embid IRUjo, A., Las libertades de la enseñanza, Madrid: Tecnos, 1983, pág. 290; Salguero Salguero, M., Libertad de Cátedra y Derechos de los Centros Educativos, cit. en núm. 15, pág. 84; Martín SÁnchez, I., La libertad de enseñanza en la jurisprudencia del Tribunal Constitucional español, Anuario de Derecho Eclesiástico del Estado, Volumen II, 1986, pág. 235; ÁlvAREZ, N., "La libertad de cátedra hoy: entre la potestad y el control», Revista de la Facultad de Derecho de la Universidad Complutense, núm. 76, 1990, pág. 28; LuCAS VERdú, P., voz «Libertad de cátedra», en Nueva Enciclopedia Jurídica, tomo XV, Barcelona: Edit. F. Seix, 1981, pág. 340; MARTínez LóPEZMuÑIZ, J. L., "La educación en la Constitución española. Derechos fundamentales y libertades públicas en materia de enseñanza», Persona y Derecho, núm. 6, 1979, pág. 276. 
momento de la investigación, en la transmisión y en la elección del método más adecuado en el proceso de investigación ${ }^{31}$.

A partir de la doble vía de análisis del contenido esencial de un derecho fijada por el Tribunal Constitucional ${ }^{32}$ se puede concluir, en la línea seguida por la doctrina anteriormente citada, que el contenido esencial de la libertad de cátedra estaría constituido por el derecho de todo profesor a expresar sus ideas y opiniones en el ejercicio de la docencia, las cuáles tendrán que guardar relación con la disciplina impartida por ese docente ${ }^{33}$. Por tanto la libertad de cátedra no permite

31 Salguero Salguero, M., Libertad de Cátedra y Derechos de los Centros Educativos, cit. en núm. 15, pág. 84. En idéntica línea Expósito afirma que este contenido esencial de la libertad de cátedra «estaría constituido por el derecho de todo profesor a expresar ideas y opiniones en el ejercicio de la docencia, ideas y opiniones que habrán de guardar necesariamente relación con la disciplina impartida por el mismo docente (...). Igualmente, se integraría en el contenido esencial del derecho la facultad de adoptar el método de enseñanza que el profesor crea más adecuado a sus explicaciones». Expósito, E., La libertad de cátedra, cit. en núm. 21, pág. 163-14. Por último, destaca la particular postura de Castillo Córdova que usa la expresión contenido constitucional, el cuál equivale, en general, a este contenido esencial: «la libertad de cátedra comprende todas aquellas facultades que permitan a su titular preparar el contenido de los mensajes educativos, disponerlos para su transmisión y transmitirlos efectivamente, incluyendo la facultad de optar por la metodología que considere más adecuada para realizar tales operaciones». CASTILlO CóRDOva, L., Libertad de cátedra en una relación laboral con ideario, cit. en núm. 7, pág. 381.

32 Recordamos en este sentido que según la Sentencia 11/81, de 8 de abril, la fijación del contenido esencial de un derecho fundamental se puede realizar mediante dos vías complementarias. Por una parte «la determinación de aquellas facultades o posibilidades de actuación necesarias para que el derecho sea reconocible como perteneciente al tipo descrito y sin las cuales deja de pertenecer a ese tipo (...) todo ello referido a un momento histórico que en cada caso se trate». Y por otro lado, «la determinación de aquella parte del contenido del derecho que es absolutamente necesaria para que los intereses jurídicamente protegibles que dan vida al derecho, resulten real, concreta y efectivamente protegidos».

${ }^{33}$ Este elemento de que las ideas y convicciones expresadas deban guardar relación con la materia objeto de enseñanza ayuda de hecho a delimitar el contenido esencial de este derecho. Partimos así de que la facultad de expresar las ideas y opiniones propias es propia de la libertad de cátedra. Pero, ¿lo es por igual en todos los niveles y en todos los casos?. Por ejemplo un profesor que imparta a sus alumnos Historia en la etapa de enseñanza Primaria no podrá nunca llegar a expresar sus ideas y convicciones de la misma manera que lo haría un profesor universitario de Historia. Pero esta diferencia se debe a que el profesor universitario, además de poder expresar sus convicciones científicas podrá también afirmar sus opiniones personales de tipo ideológico, siempre que guarden relación con la materia. Y ello porque como nos recuerda Díaz Revorio estas opiniones personales de tipo ideológico no forman parte del contenido esencial común o uniforme sino de su contenido variable. Así se deriva de lo que señala el Tribunal Constitucional al decir que en los niveles inferiores el docente «no puede orientar ideológicamente su enseñanza con entera libertad de la manera que juzgue más conforme a sus convicciones». ¿Puede entonces un profesor uni- 
enseñar lo que el profesor tenga a bien, ni expresar ideas y opiniones ajenas a la materia que imparta. Igualmente integrará este contenido esencial la facultad de adoptar el método de enseñanza que el profesor crea más adecuado a sus explicaciones ${ }^{34}$.

De aquí se deriva que el legislador no podrá afectar a este derecho del profesor a expresar sus ideas y opiniones en el ejercicio de su función docente ni tampoco podrá incidir sobre esa facultad de elección del método a través del cuál se desarrollan las explicaciones docentes. Sin embargo, las facultades de determinación de un programa o de fijación de los métodos de evaluación de los conocimientos adquiridos por el alumno sí que podrán, de acuerdo con el artículo 53.1 de la Constitución, ser reguladas y afectadas por la acción del legislador.

Llegado este punto de la exposición, parece claro, revisando el esquema argumental y lógico de la Sentencia 5/1981, de 13 de febrero, y siguiendo la opinión más actual de diversos autores ${ }^{35}$, que el contenido esencial de la libertad de cátedra coincide con el contenido negativo, el cuál se califica como uniforme, mientras que, a sensu contrario el Juez de la Constitución califica el contenido positivo como modulable y graduable en función de los niveles educativos y las competencias públicas. Es decir, si las facultades que integran el contenido positivo pueden ser afectadas por el legislador en las líneas antes detalladas, eso implica que no forman parte del contenido esencial puesto que este, por definición, es un límite infranqueable a toda actividad legislativa.

versitario desarrollar en sus clases opiniones de contenido ideológico?. Podemos responder afirmativamente, siempre que esas opiniones guarden relación con su asignatura y, a la par, el docente de niveles inferiores sí podrá expresar sus convicciones o ideas científicas puesto que ello es distinto a orientar ideológicamente su enseñanza. ¿Cómo diferenciar las convicciones e ideas científicas de las opiniones ideológicas?. Díaz Revorio reconoce que aún siendo muy difícil diferenciar en la práctica, esta labor deberá delimitarse en cada caso, puesto que en caso contrario no se podría afirmar como hace el Alto Tribunal que la libertad de cátedra implica el derecho a expresar ideas o pensamientos. Díaz Revorio, F. J., Los derechos fundamentales del ámbito educativo en el ordenamiento estatal y autonómico de Castilla-La Mancha, Toledo: Cortes de Castilla-La Mancha, 2002, pág. 94.

${ }^{34} \mathrm{Y}$ es que en palabras de Expósito «no se puede separar la libertad del profesor para ejercer la docencia que le corresponda y el método a través del cual se ejercite esta libertad, pues éste se constituye en la vía de exteriorización de la libertad que constitucionalmente se reconoce a quien enseña». EXPósıTo, E., La libertad de cátedra, cit. en núm. 21, págs. 165.

${ }^{35}$ Díaz Revorio, F. J., Los derechos fundamentales del ámbito educativo en el ordenamiento estatal y autonómico de Castilla-La Mancha, cit. en núm. 33, pág. 93; LozANo Cutanda, B., La libertad de cátedra, Madrid: Ed. Marcial Pons, UNED, 1995, pág. 178; Expósito, E., La liberta de cátedra, cit. en núm. 21, pág. 166. 


\section{LÍMITES ESPECÍFICOS AL EJERCICIO DE LA LIBERTAD DE CÁTEDRA}

Partiendo de la doctrina, reiterada por nuestro Alto Tribunal en diversidad de pronunciamientos ${ }^{36}$, recordamos ahora que al igual que ocurre con los demás derechos, el ejercicio de la libertad de cátedra no es ni absoluto ni ilimitado ${ }^{37}$. Como tal estará sometido a las barreras genéricas de todos los derechos fundamentales y al mismo tiempo, tendrá unos límites específicos derivados de su naturaleza y circunstancias de aplicación práctica. En este sentido recuerda el Tribunal Supremo que este derecho "como cualquier derecho fundamental o no, no es absoluto, ya que tienen por una parte, un concreto contenido, que determina su extensión y alcance y, por otra, se encuentra limitado y condicionado por el derecho de los demás ${ }^{38}$.

Para desarrollar y aclarar unos y otros límites resultará fundamental la función interpretativa de nuestro Tribunal Constitucional, considerando la regla general establecida por la tantas veces citada Sentencia 5/1981, de 13 de febrero que no es otra que la reafirmación del principio de modulación o variabilidad del contenido, ejercicio y, ahora también, límites de la libertad de cátedra. Ello se hace efectivo al señalar que el ejercicio de este derecho ha de efectuarse dentro de los límites propios del puesto docente que se ocupa ${ }^{39}$. Pero igualmente será necesario sacar a colación otros pronunciamientos de tribunales inferiores ya que resulta habitual el que en los conflictos que se plantean ante los tribunales en los que se invoca cualquier as-

${ }^{36}$ Principalmente la Sentencia 11/1981, de 8 de abril, que establece que ningún derecho, ni aun los de naturaleza o carácter constitucional, puede considerarse como ilimitado. En el mismo sentido la Sentencia 2/1982, de 29 de enero, FJ 5; la Sentencia 91/1983, de 7 de noviembre, FJ 4º la Sentencia 110/1984, de 26 de noviembre, FJ 5 ${ }^{\circ}$

37 Aunque, por el contrario, como señala Lucas Verdú, las limitaciones y excepciones a esta libertad no deben ser numerosas para no correr el riesgo de agotar la libertad. Así no se deben admitir las limitaciones que afecten directa o indirectamente a la esencia de esta libertad de modo que «la regla de oro que debe presidir su regulación ha de ser ésta: tanta libertad académica como sea posible, tanto orden como sea necesario». LuCAS VeRdú, P., voz «Libertad de cátedra», cit. en núm. 30, págs. 343-344.

${ }^{38}$ Sentencia del Tribunal Supremo de 10 febrero de 1987, FJ 3.

39 En este sentido Torres del Moral considera preferible referirse, más que al establecimiento de limitaciones genéricas, a la modulación en el ejercicio de esta libertad. Así la libertad de cátedra deberá ser «modulada, en cada caso, por una mayor o menor exigencia de nivel científico de los conocimientos transmitidos, por la mayor o menor madurez personal de los alumnos (lo que, a su vez, remite a la obligación de los poderes públicos de proteger a la infancia y a la juventud: artículo $20.4 \mathrm{CE}$ ) y por la naturaleza pública o privada del centro,...». TORRES DEL MORAL, A., Principios de Derecho Constitucional Español, Madrid: Facultad de Derecho de la Universidad Complutense, 1992, pág. 597. 
pecto relacionado con la docencia «se esgrima de forma casi automática el derecho a la libertad de cátedra como un escudo protector frente a las políticas organizativa de los gestores de los centros educativos ${ }^{40}$. De esta manera, con este uso procesal ${ }^{41}$ de la libertad de cátedra se ha obligado a nuestros tribunales a realizar una doble labor. Por una parte, al no existir una definición legal o constitucional expresa los tribunales en su labor de interpretación y aplicación de las leyes han desmenuzado qué actividades docentes forman parte del contenido de esta libertad y cuáles no. Por otro lado en estos pronunciamientos se ha ido delimitando lo que debe entenderse por libertad de cátedra amparando con ello las conductas que son manifestaciones legítimas de la misma.

\section{III.1. El rigor científico y la ausencia de adoctrinamiento o de proselitismo en el centro docente}

Partiendo del hecho de que el objeto de la función docente es la transmisión al alumnado de conocimientos científicos resulta evidente que la libertad de cátedra no amparará la exposición de doctrinas contrarias a los postulados científicos ni tampoco aquellas que se realizasen al margen de la enseñanza. En todo caso supondrá el derecho del profesor a desarrollar su actividad libremente pero siempre con arreglo a un criterio serio y objetivo. Así el docente no podrá prevalerse de la función que ejerce para exponer o defender

40 Celador Angón, O., El Derecho de Libertad de Cátedra. Estudio Legal y Jurisprudencial, Madrid: BOE, 2007, págs. 163-4.

${ }_{41}$ Tenemos un ejemplo reciente de lo aquí señalado en las diversas sentencias que se han ido produciendo por parte de las Salas de lo Contencioso Administrativo de diversos Tribunales Superiores de Justicia en relación con la objeción de conciencia a la asignatura de Educación para la Ciudadanía. En muchos casos las partes han utilizado referencias indirectas a la libertad de cátedra como argumentación de sus posiciones. Más concretamente, en una Sentencia del Juzgado de lo Contencioso-Administrativo de Valencia de 23 de junio de 2009 se resuelve el recurso de un profesor de instituto contra la Orden de la Conselleria de Educación valenciana por la que se establece la impartición de la asignatura Educación para la Ciudadanía y los Derechos Humanos en inglés y con dos profesores en el aula. En opinión del recurrente con ello se producía una vulneración de su derecho a la libertad de cátedra. Pero el juez considera que pese a la dificultad de la metodología impuesta por la Orden recurrida, la libertad de cátedra no está afectada en ningún modo, «sin obviar la falta de potestad del profesor de inglés para incidir en la libertad individual docente del profesor titular, debiendo seguir sus pautas y transmitiendo los conocimientos e ideas expuestos por él». Se desestima el recurso ya que «no puede identificarse el derecho a la libertad de cátedra como la potestad de su titular a autorregular íntegramente y por sí mismo la función docente». 
cuestiones ajenas a la ciencia, no podrá ampararse en una libertad absoluta de enseñar.

Consecuentemente bajo el ejercicio de la libertad de cátedra no se protegerá una supuesta libertad de propaganda política en el centro docente, quedando así excluidos el dogmatismo y el adoctrinamiento $^{42}$. Tampoco encuentran cobertura las opiniones ideológicas que se realicen al margen de la enseñanza o, aun siendo referidas a ella, se hagan sin el menor rigor científico. El propio Tribunal Constitucional se ha referido a este aspecto al señalar, en relación con la neutralidad ideológica de la enseñanza en los centros públicos, que ésta «impone a los docentes que en ellos desempeñan su función una obligación de renuncia a cualquier forma de adoctrinamiento ideológico, que es la única actitud compatible con el respeto a la libertad de las familias que, por decisión libre o forzada por las circunstancias no han elegido para sus hijos centros docentes con una orientación determinada y explícita ${ }^{43}$.

En este mismo sentido y más recientemente, el Tribunal Supremo -en relación con el derecho a la objeción de conciencia aplicado a la asignatura de Educación para la Ciudadanía - una vez reconocido que la asignatura controvertida es ajustada a Derecho y que resulta válido el deber jurídico de cursarla, ha establecido que ello «no autoriza a la Administración educativa -ni tampoco a los centros docentes, ni a los concretos profesores- a imponer o inculcar, ni siquiera de manera indirecta, puntos de vista determinados sobre cuestiones morales que en la sociedad española son controvertidas. Por lo tanto, «las asignaturas que el Estado, en su irrenunciable función de programación de la enseñanza, califica como obligatorias no deben ser pretexto para tratar de persuadir a los alumnos sobre ideas y doctrinas $(\ldots){ }^{44}$.

Concluimos así que la actividad docente, en cuanto transmisión

42 En opinión de FERNÁNDEZ MiRANDA el profesor «transmite al alumno valores y pautas de comportamiento, enfoques sobre el objeto de conocimiento que en muchos casos serán tan lícitos como discutibles, distinguiendo entre lo que puede ser una percepción subjetiva, más o menos discutible, pero respetuosa, de lo que sería el adoctrinamiento dogmático y la manipulación de las conciencias». FERNÁNDEZ-MiRANDA Y CAmpoamor, A., y Sánchez Navarro, A. J., «Artículo 27. Enseñanza», en Comentarios a la Constitución Española de 1978, tomo III, dir. por Alzaga VILLAMIL, Madrid: Edersa, 1997, págs. 243-244.

43 Sentencia 5/81, de 13 de febrero, FJ $9^{\circ}$.

${ }_{44}$ Sentencia del Pleno de la Sala Tercera de lo Contencioso-Administrativo del Tribunal Supremo, de 11 de febrero de 2009, dictada frente al recurso de casación núm. 1013/2008, Fundamento Jurídico decimoquinto. 
de conocimientos deberá responder a las exigencias que el rigor científico impone, límite íntimamente relacionado con otros que seguidamente abordaremos como el contenido de las asignaturas que se deben impartir ${ }^{45}$.

\section{III.2. La libertad de conciencia de los alumnos}

La libertad de cátedra se encuentra limitada por el necesario respeto a la libertad de conciencia de los alumnos habida cuenta de que los derechos de los niños y jóvenes, como destinatarios directos del ejercicio de esta libertad suponen, de hecho, un claro límite a la misma. La importancia de este límite en el ámbito de la docencia deriva de factores psico-antropológicos como la edad, la madurez personal y afectiva o la capacidad de reflexión y crítica de los alumnos, situando la delimitación cronológica en los dieciocho años ${ }^{46}$. Y en esta línea se podría acuñar la máxima de «a mayor capacidad crítica del alumno, mayor libertad del profesor, siempre, desde luego con el debido respeto a la objetividad científica y a la verdad» ${ }^{47}$. Por otro lado recordamos ahora que el propio Tribunal Constitucional asienta su línea doctrinal al respecto sobre la consideración de estos factores o condicionantes para aseverar que el contenido positivo de este derecho es necesariamente gradual y va disminuyendo en función del nivel educativo. $\mathrm{Y}$ en este contexto CELADOR ANGÓN ${ }^{48}$ alerta sobre el

45 En este sentido recordamos que, en relación con la enseñanza no universitaria, la disposición adicional cuarta de la Ley Orgánica 2/2006, de 3 de mayo, de Educación hace referencia expresa a esta exigencia de rigor científico con el siguiente tenor literal: «En el ejercicio de la autonomía pedagógica, corresponde a los órganos de coordinación didáctica de los centros públicos adoptar los libros de texto y demás materiales que hayan de utilizarse en el desarrollo de las diversas enseñanzas. La edición y adopción de los libros de texto y demás materiales no requerirán la previa autorización de la Administración educativa. En todo caso, éstos deberán adaptarse al rigor científico adecuado a las edades de los alumnos y al currículo aprobado por cada Administración educativa (...)».

46 Salguero Salguero, M., Libertad de Cátedra y Derechos de los Centros Educativos, cit. en núm. 15, pág. 98. Ver además los artículos 2 y 3 de la Ley Orgánica 8/1985, de 3 de julio, reguladora del Derecho a la Educación (LODE).

${ }^{47}$ FERnÁNDEZ-Miranda y CAMPOAMOR, A., De la libertad de enseñanza al derecho a la educación, cit. en núm. 54, pág. 140. Esta fue de hecho una de las cuestiones más debatidas durante los debates parlamentarios en torno a la elaboración del precepto del 20.1 c) de la Constitución. Así por ejemplo Alzaga afirmaba en torno al reconocimiento y alcance de esta libertad lo siguiente: «No hay al menos otro problema que el del nivel del alumnado, dimanente de la edad del alumnado...(...). A menor edad menor libertad de cátedra porque hay que respetar la juventud y la infancia». AlzAGA VILLAAMIL, O., DSCD, núm. 72, pág. 4822.

48 Celador Angón, O., El Derecho de Libertad de Cátedra. Estudio Legal y Juris- 
hecho de que el ejercicio de este contenido positivo supone también el que los docentes puedan optar por el método pedagógico y docente que estimen más adecuado, elección que en algunos casos podría lesionar la libertad de conciencia de sus alumnos.

Por último, debemos destacar que el propio legislador ha tenido en cuenta estos factores de edad, madurez y capacidad crítica como referentes de la actividad educativa. Así lo ha plasmado, de manera expresa o tácita, en la diversidad de normas educativas de los últimos treinta años. Sirva como ejemplo el propio artículo 6.3 e) de la Ley Orgánica 8/1985, de 3 de julio, reguladora del Derecho a la Educación (L.O.D.E.) que recoge el derecho de los alumnos «a que se respete su libertad de conciencia, sus convicciones religiosas y sus convicciones morales, de acuerdo con la Constitución ${ }^{49}$.

\section{III.3. Las normas de organización de la docencia y del centro}

Resulta obvio que la libertad de cátedra está sometida a una serie de límites organizativos conformados por todas aquellas normas que regulan la organización de la docencia y también los criterios de examen y evaluación de los alumnos. Así pues no puede suponer una absoluta libertad de enseñar prescindiendo de las normas de organización del centro y de aquellas otras que regulan el régimen académico de la enseñanza. Por lo tanto, el docente de cualquier nivel educativo viene obligado a cumplir la normativa sobre horarios, sistemas de evaluación y en general todas aquellas que regulen la mecánica administrativa de la docencia e investigación.

En el ámbito no universitario, habida cuenta de su menor autonomía en relación con los centros docentes universitarios, parece

prudencial, cit. en num. 40, pág. 176. En esta línea destaca la Sentencia de 15 de septiembre de 2004 de la sala de lo Contencioso-Administrativo del Tribunal Superior de Justicia de Madrid, dictada ante el recurso presentado por las padres de una alumna de $3^{\circ}$ de Bachillerato del Instituto Español de Lisboa, la cual fue sometida a un expediente disciplinario debido a su falta de asistencia a las clases de inglés, ausencia justificada por sus padres alegando el comportamiento inmoral del profesor de la asignatura.

${ }_{49}$ En opinión de Otaduy Guerin este derecho de los alumnos a que se respete su libertad de conciencia «obliga a respetar la libre determinación personal en materias morales y a mantener, por parte de los profesores y del conjunto del aparato público, la adecuada reserva sobre lo que pueda afectar a la formación de la conciencia de los menores». OTADUY GUERIN, J., «Neutralidad ideológica del estado y del sistema educativo público», Ponencia en la Jornada de Estudio de Educación para la Ciudadanía, Madrid: Conferencia Episcopal Española, 2006, pág. 8. 
igualmente claro el mayor peso y amplitud de estos límites organizativos. En estos niveles inferiores de enseñanza el docente estará sometido a una amplia normativa básica y de desarrollo como son todas las prescripciones por las que se regula la organización y funcionamiento de los centros docentes, así como otros aspectos tan importantes, en relación con esta libertad, como las atribuciones docentes en función de las diferentes especialidades del profesorado ${ }^{50}$. En toda esta normativa se delimita también con claridad la existencia de los Departamentos didácticos, su funcionamiento y coordinación horizontal y vertical con el resto de órganos colegiados y de gobierno. Se articula por tanto todo un entramado organizativo, curricular y didáctico por el que cada docente no universitario tendrá claramente delimitadas las principales cuestiones de referencia para su ejercicio profesional: las asignaturas, materias o módulos que debe impartir así como las especialidades afines que en su caso podrán completar su carga lectiva; su inclusión, a efectos de organización y supervisión en uno de los múltiples Departamentos Didácticos que pueden existir en un centro, siempre en función de las etapas educativas que se impartan en el mismo; su jornada lectiva; las normas que regulan la evaluación académica de sus alumnos y sus ámbitos de participación en el gobierno, organización y funcionamiento de su centro de destino.

Estos límites organizativos de la libertad de cátedra no suponen generalmente fuente de problemas jurídicos de interpretación y aplicación como demuestra por un lado la casi inexistente jurisprudencia

50 Para entender este entramado normativo: a partir de la normativa básica de Ley Orgánica 2/2006, de 3 de mayo, de Educación, cuyo Titulo V se centra en la participación, autonomía y gobierno de los centros existen otras normas de desarrollo como el Real Decreto 83/1996, de 26 de enero, por el que se aprueba el Reglamento Orgánico de los Institutos de Educación Secundaria, dictado en el ámbito de gestión de todo el territorio nacional y adaptado a cada Comunidad Autónoma. Y ya dentro de las Comunidades Autónomas (usemos de ejemplo el caso del Principado de Asturias) esta organización y funcionamiento se articula a través de la Resolución de 6 de agosto de 2001, de la Consejería de Educación y Cultura, por la que se aprueban las instrucciones que regulan la organización y funcionamiento de los Institutos de Educación Secundaria del Principado de Asturias y la Resolución de 6 de agosto de 2001, de la Consejería de Educación y Cultura, por la que se aprueban las instrucciones que regulan la organización y el funcionamiento de las Escuelas de Educación Infantil y de los Colegios de Educación Primaria del Principado de Asturias. Todas estas normas se adaptan, cada curso escolar, a concretas prescripciones organizativas y curriculares por medio de las Circulares de Inicio de curso. Además para supervisar y controlar este entramado organizativo de los centros, los currículos y todos los aspectos prácticos de la docencia en los que se incardina la función de cada profesor, se encuentra por una parte la Alta Inspección, dependiente del Ministerio de Educación y Ciencia y, por otra ya en el ámbito de cada Comunidad, la Inspección Educativa. 
constitucional ${ }^{51}$ al respecto $y$, por otro, la escasez de pronunciamientos de órganos jurisdiccionales inferiores a nuestro Alto Tribunal ${ }^{52}$.

\section{III.4. La programación de la disciplina a impartir}

El docente deberá adecuar su actividad diaria a la programación de la enseñanza a impartir y ello considerando el propio fin educativo: transmitir unos determinados conocimientos que, al estar inscritos en un determinado plan de estudios que incluye otras asignaturas, hace posible que los alumnos accedan al nivel de conocimientos que se pretende con el mismo. Por lo tanto al profesor se le exigirá ejercer su docencia bajo los parámetros de un saber -área, disciplina, cuerpo

51 De hecho la intervención de la jurisprudencia constitucional en relación con el derecho a la educación del artículo 27 de la Constitución ha ido descendiendo en los últimos años. Así según las Estadísticas publicadas por el propio Alto Tribunal, en el año 2008 se turnaron a las Salas, invocando este derecho fundamental, sólo 8 recursos (el 0,08\% del total), los mismos que en el 2007; en el 2006 el número de recursos de amparo de esta tipología fueron 9 y en el 2005, fueron 16.

${ }_{52} \mathrm{Y}$ esta ausencia de conflictos resultará más evidente sí consideramos como una cuestión controvertida aparte todos los conflictos derivados de la relación entre libertad de cátedra y el ideario de los centros docentes privados, ya que en este preciso campo sí que va a existir una mayor incidencia de pronunciamientos judiciales ante, por ejemplo, supuestos de extinción contractual de docentes relacionados con su práctica profesional. En este sentido la mayor parte de los pronunciamientos jurisdiccionales en los que se ha invocado, con mayor o menor protagonismo sobre el fondo del asunto, la libertad de cátedra -y ello sin considerar la primigenia Sentencia del Tribunal Constitucional 5/1981, de 13 de febrero, en la que como hemos ido desbrozando a lo largo del presente trabajo se hacen múltiples referencias genéricas a la libertad de cátedra en los niveles inferiores- se han producido en las Salas de lo Contencioso-Administrativo de los Tribunales Superiores de Justicia en relación con supuestos de revisión de calificaciones, modificación de programaciones docentes o expedientes disciplinarios en los que según la pretensión del recurrente se afectaba la libertad de cátedra. Baste adelantar ahora como síntesis de la línea argumentativa de estos procedimientos lo que señaló la Sección Primera de la Sala de lo Contencioso Administrativo del Tribunal Superior de Justicia de Andalucía en su Sentencia núm. 64/2003, de 20 de octubre: «En definitiva, si sólo la defensa de la libertad de cátedra legitimaba a algunos recurrentes para la interposición del recurso, y si no han podido ofrecerse razones que acrediten que la resolución impugnada conculcó ese derecho, el recurso deberá desestimarse, sin poder entrar en si el criterio técnico seguido por la Administración para aprobar a la alumna Doña Fátima Lillo fue o no más correcto que el mantenido por los recurrentes, pues para ese aspecto particular carecían de legitimación todos los recurrentes, dado que la libertad de cátedra no es una ventana falsa por la que puedan acceder a la jurisdicción la meras discrepancias técnicas (ajenas por completo a opiniones o expresión de ideas, o a la misma concepción profunda de la metodología de la docencia que se imparte) existentes entre el profesor funcionario que evalúa y el órgano administrativo superior que tienen por ley encomendada la misión de revisar esa evaluación». Fundamento Jurídico $3^{\circ}$, in fine. 
de conocimientos- para el cuál ha sido contratado o ha superado unas oposiciones. Aún más, ya en relación con el deber de enseñar el profesor ha de enseñar desde su puesto docente y no puede enseñar lo que mejor le parezca sino que debe transmitir la materia objeto de su enseñanza. En este sentido no vulnera la libertad de cátedra las normas, como es el caso del régimen disciplinario de la Ley 7/2007, de 12 de abril, del Estatuto Básico del Empleado Público o de las Leyes autonómicas de Función Pública, que exigen responsabilidades al profesorado por falta de idoneidad didáctica o de ineptitud en la docencia $^{53}$.

Por otro lado, pese a que algunos autores ${ }^{54}$ entienden que este limite es bastante complejo de determinar en el caso de algunas disciplinas -como las que integran las ciencias sociales y humanas al tener

53 De hecho, centrándonos en el ámbito de mayor interés para este trabajo, la enseñanza no universitaria, una de las funciones de la Inspección educativa es según el artículo 151 de la Ley Orgánica 2/2006, de 3 de mayo, de Educación supervisar y controlar la práctica docente (...) y supervisar y controlar desde el punto de vista pedagógico y organizativo el funcionamiento de los centros educativos. De esta labor de supervisión se derivan, en la enseñanza pública, los expedientes disciplinarios incoados a funcionarios ante las irregularidades en el desempeño de la función muchas de ellas relacionadas con lo que indirectamente podríamos denominar libertad de cátedra mal entendida. Por citar un ejemplo de referencia, en el ámbito de la Comunidad Autónoma del Principado de Asturias se incoan una media de 20 expedientes disciplinarios por curso escolar -sobre una total de plantilla media de 11.300 profesores cada curso escolar, en las diversas categorías de funcionarios de carrera, de prácticas, interinos y personal laboral docente- de los cuáles un 30\% corresponden a situaciones de incumplimiento de programación o ineptitud del docente para impartir contenidos. Son los denominados expedientes de competencia pedagógica. Un ejemplo de estos expedientes de competencia pedagógica es el de la Resolución del Consejero de Educación y Ciencia de 1 de abril de 2008 que aborda el supuesto de un profesor del ámbito sociolingüístico de los programas de Diversificación y Apoyo, respecto del cuál el Inspector instructor considera probados los siguientes hechos:»...incurre en una desviación y apartamiento graves de su práctica docente respecto de la programación didáctica, tanto en el plano de los objetivos y contenidos como en el de los criterios de evaluación y calificación. Como consecuencia, se produce también una grave conculcación de los derechos básicos de aprendizaje y valoración que asisten a los alumnos de $3^{\circ}$ y $4^{\circ}$ de ESO, que siguen en el Programa de Diversificación Curricular». También se considera probado el que «ha desarrollado en el aula, a lo largo del año 2006-0,7 una labor docente que se aparta, de forma significativa y de manera no motivada, de lo establecido en la programación didáctica, y que carece, especialmente en los dos primeros trimestres del curso, de los instrumentos de evaluación básicos para poder realizar un seguimiento documentado del proceso de aprendizaje de los alumnos, con la consecuente repercusión en el derecho de éstos a que su rendimiento escolar sea valorado con plena objetividad».

54 Prieto DE PEDRo, J., «Consideraciones sobre la enseñanza en la Constitución», en Lecturas sobre la Constitución española, vol. II, dir. por FERNÁNDEZ RodRíGUEZ, T. R., Madrid: UNED, 1978, pág. 528. 
todas ellas unas premisas de contenidos afines- o incluso para algunos niveles de enseñanza, en el que el docente imparte varias asignaturas, lo cierto es que nos encontramos ante un límite a la libertad de cátedra necesario y materialmente lógico: todo profesor está sujeto al programa de la asignatura o área que imparte, desde el cuál resulta condicionado en su labor por el contenido mínimo aprobado a través de los planes de estudios, por los poderes públicos en el caso de los niveles no inferiores, o por los Departamentos en el caso de la enseñanza universitaria ${ }^{55}$. Respecto a los niveles no universitarios de enseñanza se trata de garantizar con mayor intensidad un nivel esencial de conocimientos que asegure la igualdad de todos los españoles ante el contenido esencial de la educación. Concretamente, respecto de la enseñanza no universitaria, la organización y definición del currículo constituye uno de los pilares centrales del sistema educativo que se articula sobre la premisa de una propuesta básica y común de currículo en todo el estado español y, de manera complementaria, con la aceptación de un currículo abierto y flexible a través del cuál se trata de dar cabida a lo que de específico tiene cada realidad educativa. Así el denominado, en la terminología educativa, diseño curricular se articula en sucesivos niveles de concreción. En un primer nivel, la Administración educativa de cada Comunidad Autónoma, completa y adecua a su contexto cultural y socioeconómico las prescripciones contenidas en los Reales Decretos de Título y/o currículo aprobados por el Ministerio de Educación como marco uniforme estatal. En un segundo nivel, el de cada centro, los equipos docentes, en el marco de un Proyecto Educativo de Centro, concretan y adaptan ese currículo al contexto más específico elaborando el Proyecto $\mathrm{Cu}$ rricular de Etapa. Por último, en un tercer nivel, nos encontramos con la Programación de Aula, cuyas directrices generales serán aprobadas y elaboradas por los Departamentos didácticos, quedando siempre relativos márgenes de individualización por parte de cada profesor $^{56}$.

55 Coarasa, C., La libertad de enseñanza en España, cit. en núm. 9, pág. 231; ExPóSiтo, E., La libertad de cátedra, cit. en núm. 21, pág. 217.

${ }^{56}$ A priori puede parecer que según la normativa en vigor al respecto la elaboración de una programación es un proceso jerárquico, burocrático, cerrado y altamente controlado. Así centrándonos en el ejemplo de un Instituto de Educación Secundaria, la normativa aplicable es el Real Decreto 83/1996, por el que se aprueba el Reglamento Orgánico de los Instituto de Educación Secundaria y, en el caso de la Comunidad Autónoma del Principado de Asturias, la Resolución de 6 de agosto de 2001, de la Consejería de Educación y Cultura, por la que se aprueban las instrucciones que regulan la organización y funcionamiento de los Institutos de Educación Secundaria del Principado de Asturias. Pues bien según el artículo 49 del Real Decreto 83/1996 una de las competencias de cada Departamento será «elaborar, antes del co- 
Con este entramado organizativo y pedagógico, parece evidente que, desde una perspectiva más restrictiva de la libertad de cátedra en este nivel no universitario ${ }^{57}$, el profesor individualmente considerado tiene una capacidad muy limitada para determinar el contenido y el método de su asignatura, módulo o materia. Y además se concluirá que esta limitación será mayor conforme menor sea la edad de los alumnos. En este sentido, se puede defender que el contenido positivo de la libertad de cátedra, entendido como libre determinación de la actividad docente, tendrá aquí un alcance más reducido que respecto al nivel universitario. Ello implicará que esta vertiente de la libertad se configurará, «en realidad como una discrecionalidad técnica equivalente a la de cualquier otro profesional que ejerza una tarea que le haya sido encomendada en razón de su preparación cualificada en una determinada ciencia 0 arte ${ }^{58}$.

Por el contrario, desde una visión más abierta de la labor del docente no universitario, se podría defender que es en este nivel de individualización dónde ejerce, dentro de las limitaciones generales y específicas que estamos desarrollando, un mayor juego la libertad de cátedra. En este sentido en el preámbulo de la Ley Orgánica 2/2006, de 3 de mayo, de Educación se hace referencia a «la existencia de un marco legislativo capaz de combinar objetivos y normas comunes con la necesaria autonomía pedagógica y de gestión de

mienzo del curso académico, la programación didáctica de las enseñanzas correspondientes a las áreas, materias y módulos integrados en el departamento, bajo la coordinación y dirección del jefe del mismo, y de acuerdo con las directrices generales establecidas por la comisión de coordinación pedagógica. La programación didáctica incluirá, para cada etapa, los aspectos señalados en el artículo 68 de este Reglamento».A su vez este artículo recoge una serie de aspectos que toda programación incluirá necesariamente en función de las etapas educativas como por ejemplo, en el caso de la educación secundaria obligatoria, los objetivos, los contenidos y los criterios de evaluación para el primer ciclo y para cada uno de los cursos del segundo ciclo. Y por último, este círculo de control y supervisión sobre la práctica docente se cierra al establecer las normas autonómicas como el apartado 1.2.2 de la Resolución de 6 de agosto de 2001 de la Consejería de Educación del Principado de Asturias que «la Comisión de Coordinación Pedagógica comprobará que las programaciones didácticas se ajustan a las directrices de dicha comisión, a lo establecido en el artículo 68 del Reglamento Orgánico de los Institutos y en estas Instrucciones. En caso contrarío, el Director devolverá al departamento la programación didáctica para su reelaboración. Los jefes de Departamento velarán por que el desarrollo de las programaciones didácticas se ajuste a lo establecido en las mismas. El Servicio de Inspección Educativa y de Servicios revisará las programaciones para comprobar su adecuación a la normativa y comprobará, periódicamente en una muestra de centros, el correcto desarrollo y aplicación de las programaciones a lo largo del curso».

57 Lozano Cutanda, B., La libertad de cátedra, cit. en núm. 37, pág. 210-211.

58 Ibidem, pág. 210. 
los centros docentes». Y es que en el espíritu de esta norma base se trata de impulsar la autonomía de los centros, la cuál a su vez implicará el reconocimiento de un correlativo nivel de autonomía de sus docentes. En este sentido el artículo 120 de la citada Ley remarca que «los centros dispondrán de autonomía pedagógica» y, en conexión más directa con la libertad de cátedra, el artículo 121 señala que «corresponde a las Administraciones educativas contribuir al desarrollo del currículo favoreciendo la elaboración de modelos abiertos de programación docente y de materiales didácticos que atiendan a las distintas necesidades de los alumnos y del profesorado». La citada expresión, modelos abiertos de programación docente, resulta clave ya que se refiere, precisamente, a que estas programaciones no están cerradas desde los otros dos niveles, esto es, no son meras concreciones curriculares. Antes al contrario, el docente, en atención a la diversidad de realidades educativas y a sus enfoques y aprendizajes personales, y siempre respetando lo que podríamos denominar suelo mínimo de lo que se debe enseñar, disfruta de un espacio para exponer y transmitir su saber científico sin mayores trabas que las anteriormente delimitadas ${ }^{59}$.

\section{III.5. El deber de enseñar}

Se refiere este límite al hecho de que la libertad de cátedra -a diferencia de otras libertades como es el caso de la libertad de asociación que supone el derecho a no asociarse- no puede, en ningún caso, significar la libertad de no enseñar. En este sentido una norma que asocie determinadas consecuencias jurídicas a los supuestos de falta de idoneidad didáctica del profesor o ineptitud en la docencia no supondría conculcar en ningún caso la liberta de cátedra. Así en relación con la intervención administrativa sobre el profesorado la Administración educativa supervisa su práctica docente a través de la Inspección educativa que podrá incoar expedientes disciplinarios con los que a un funcionario, interino o de carrera se le podría separar del servicio.

59 En este sentido el apartado 3 del artículo 68 del Real Decreto 83/1996, por el que se aprueba el Reglamento Orgánico de los Instituto de Educación Secundaria, comienza estableciendo que «los profesores desarrollarán su actividad docente de acuerdo con las programaciones didácticas de los departamentos a los que pertenezcan», pero a la par acepta variaciones y aportaciones individuales siempre y cuando respeten «las decisiones generales adoptadas en el proyecto curricular de la etapa correspondiente». 
Resumidamente, en relación con este límite, sirvan ahora las palabras de la Sentencia del Juzgado de lo Social de Sevilla, núm. 100/2001, de 31 de marzo en la que una vez configurada como servicio público la función docente se afirma que ello «delimita, por consiguiente, el derecho a la libertad de cátedra, restringiendo su titularidad a los profesionales de la docencia y encauzando su ejercicio, que no comprende ni la libertad de no enseñar, ni la libertad de expresar ideas completamente ajenas al contenido de la enseñanza. Si el docente tiene el deber de enseñar, no cabe duda de que la enseñanza debe regularse de tal modo que no se viole la libertad, pero que se garantice al mismo tiempo que ésta no se traduzca en una falta de enseñanza» ${ }^{60}$.

\section{III.6. El artículo 27.2 de la Constitución referido al objeto de la educación}

De acuerdo con el artículo 27.2 de la Constitución el objeto de la educación es doble, por un lado, el pleno desarrollo de la personalidad humana y por otro, el respeto a los principios democráticos de convivencia y a los derechos y libertades fundamentales. Este límite estará relacionado con el anteriormente señalado del rigor científico ${ }^{61}$ y, principalmente, con el adecuado respeto al contenido de la disciplina que imparte el docente en cada caso concreto. Será además un límite aplicable en todos los niveles de enseñanza, no sólo en el nivel de educación primaria y secundaria, niveles estos en los que además, el propio artículo 27.2 establece el fundamento de la protección de la

${ }^{60}$ Sentencia 100/2001, de 31 de marzo, del Juzgado de lo Social núm. 4 de Sevilla, FJ 2, párrafo 5. En este caso se considera nulo el despido de un profesor el cual da sus clases en un centro cuyo ideario es el del Opus Dei, ideario que se manifiesta, entre otras cosas, en la práctica de la preceptuación, consistente en que al profesor se le entrega una hojilla con los alumnos que deben salir de clase, los cuales van saliendo de uno en uno, y tras la ello regresar a la clase, la cual es sucesivamente interrumpida. El Juez considera que se vulnera su libertad de cátedra puesto que «la práctica del centro Altair, durante todo el curso escolar, supone un atentado a la libertad de cátedra del actor, entendiendo ésta en la forma antes reseñada. Es difícil entender cómo se puede dar clase, con 7 u 8 interrupciones por hora lectiva».

${ }^{61}$ Efectivamente, en este supuesto nos encontramos ante un límite a la posibilidad que tiene el profesor de orientar ideológicamente su enseñanza, aspecto éste imbricado en el contenido positivo de la libertad de cátedra. En este sentido Cámara Villar entiende que la declaración de este artículo 27.2 limita a la libertad de cátedra en cuanto que supone que el docente no puede orientar ideológicamente su enseñanza en una manera absolutamente libre o más conforme a sus propias ideas o convicciones. Cámara Villar, G., "Sobre el concepto y los fines de la educación en la Constitución española», Jornadas de Estudio. Introducción a los derechos fundamentales, vol. III, Madrid: Ministerio de Justicia, 1988, pág. 2189. 
juventud y de la infancia y de la neutralidad, en el sentido del adoctrinamiento ${ }^{62}$.

Como en anteriores ocasiones, las dimensiones y consecuencias de este límite no han sido unívocamente entendidas por la doctrina. Así ZuMAQUero ${ }^{63}$ defiende que la intencionalidad de este artículo «no es instruir a los educandos sobre el sistema constitucional español, ya que hay una asignatura específica que se ocupa de ello; ni mucho menos intentar convencerles -a través de la teoría o de la praxis- de la excelsitud de los sistemas democráticos, ya que esto último podría lesionar la libertad de enseñanza». Por el lado contrario, encontramos la postura de LOZANO ${ }^{64}$ quién, conectándola con el deber de fidelidad a la Constitución y la defensa activa de los valores constituciona$\operatorname{les}^{65}$, considera que la enseñanza es una actividad dirigida «no únicamente a la transmisión de conocimientos, sino también a la formación de valores». Ciertamente esta postura parece encontrar refrendo del propio Tribunal Constitucional quién en la tantas veces citada Sentencia 5/1981, de 13 de febrero, afirma que la enseñanza es «una actividad encaminada de modo sistemático y con un mínimo de continuidad a la transmisión de un determinado cuerpo de conocimientos y valores (...) » ${ }^{6}$. De aquí que, el Alto Tribunal se refiera, seguidamente, a la limitación de este artículo 27.2 calificándola como muy importante en el sentido de que «la enseñanza ha de servir a determinados valores (principios democráticos de convivencia, etcétera) que no cumplen una función meramente limitativa, sino de inspiración positiva ${ }^{67}$. Por su parte el propio legislador ha plasmado en su normativa este aspecto limitador al señalar a lo largo del tiempo y en distintas normas educativas que la educación tendrá como fin el pleno desarrollo de la personalidad del alumno ${ }^{68}$.

62 Salguero Salguero, M., Libertad de Cátedra y Derechos de los Centros Educativos, cit. en núm. 15, pág. 103.

63 Zumaquero Romero, J. M., Los derechos educativos en la Constitución Española de 1978, Pamplona: EUNSA, 1984, pág. 272-3.

${ }^{64}$ Lozano Cutanda, B., La libertad de cátedra, cit. en núm. 37, págs. 214.

65 Coincidiendo así con la postura de Embid Irujo que en relación con los niveles no universitarios entiende que «la condición específica del profesor más que posibilitar ataques a la Constitución, lo que hace es obligar a lo contrario: a la defensa activa de los valores constitucionales». EMBID IRUJo, A., Las libertades de la enseñanza, cit. en núm. 30, págs. 306.

${ }^{66}$ Sentencia $5 / 81$, de 13 de febrero, FJ $7^{\circ}$, párrafo $2^{\circ}$.

${ }_{67}$ Sentencia $5 / 81$, de 13 de febrero, FJ $7^{\circ}$, párrafo $3^{\circ}$.

68 Así el artículo 2 a) de la Ley Orgánica 8/1985, de 3 de julio, reguladora del Derecho a la Educación (L.O.D.E.) señala que «la actividad educativa, orientada por los principios y declaraciones de la Constitución, tendrá, en los centros docentes a que se 
En conexión con estos planteamientos, es necesario señalar, respecto al nivel de enseñanza no universitaria, la existencia del denominado currículo oculto entendido éste como aquellos contenidos educativos que deben ser abordados -desde el enfoque de todas las áreas, módulos o asignaturas- como orientaciones para incorporar a través de ellas cuestiones como la educación moral y cívica, la educación ambiental, la educación vial o la educación para la paz y la igualdad de oportunidades. Se trata de los denominados temas transversales así conceptuados "porque no corresponden de modo exclusivo a una única área educativa, sino que están presentes de manera global en los objetivos y contenidos de todas ellas y deben ser responsabilidad de todo el profesorado ${ }^{69}$. Tomando en consideración el sentido y aplicación de estos temas transversales, LOZANO ${ }^{70}$ defiende que los profesores de los niveles no universitarios de enseñanza no sólo están sometidos a los límites internos de la función docente sino que se hallan además obligados a imprimir una determinada orientación ideológica a sus enseñanzas para formar a los alumnos en los valores consagrados por nuestra Norma Fundamental. Por lo tanto esta vinculación positiva a la Constitución implicará un límite a la libertad de cátedra de los docentes no universitarios «que se superpone a otros, como son el principio de neutralidad ideológica de la enseñanza pública $(\ldots) \gg^{71}$.

\section{III.7. La lealtad del docente a la Constitución}

Otro enfoque complementario de este problema consiste en plantearse la existencia o no de un deber de lealtad del docente a la Constitución. Como punto de partida hemos de considerar que nuestra Carta Magna carece de un precepto similar al artículo 5.3, in fine, de

refiere la presente Ley, los siguientes fines: a) El pleno desarrollo de la personalidad del alumno. b) La formación en el respeto de los derechos y libertades fundamentales, de la igualdad entre hombres y mujeres y en el ejercicio de la tolerancia y de la libertad dentro de los principios democráticos de convivencia». En el mismo sentido el artículo 2 de la Ley Orgánica 2/2006, de 3 de mayo, de Educación, dice que «el sistema educativo español se orientará a la consecución de los siguientes fines: a) El pleno desarrollo de la personalidad y de las capacidades de los alumnos. b) La educación en el respeto de los derechos y libertades fundamentales (...)».

${ }^{69}$ Así lo establece la Resolución de la Secretaría de Estado de Educación, de 7 de septiembre de 1994 que desarrolla expresamente el concepto de temas transversales.

70 Lozano Cutanda, B., La libertad de cátedra, cit. en núm. 37, pág. 217.

71 Ibidem. Desde esta perspectiva de Lozano la auténtica libertad de cátedra se encuentra en el ámbito universitario, con una enseñanza científica y dirigida a alumnos ya formados. 
la Ley Fundamental de Bonn, según el cuál la libertad de enseñanza entendida como libertad de cátedra «no exime de la fidelidad a la Constitución».

A partir de aquí, y en conexión directa con los debates reproducidos en el anterior apartado, una parte de la doctrina ha defendido la existencia de este límite, considerando así que el profesor en sus explicaciones ha de atenerse a los postulados recogidos en la Constitución, siendo además un elemento clave la condición funcionarial o no del docente. Así por ejemplo para EMBID ${ }^{72}$ la actitud del docente -refiriéndose sólo al funcionario y en los niveles inferiores- ante la Constitución debe ser de respeto y por ende, este respeto limitará necesariamente la propia libertad de cátedra. Sin embargo, para ExPó$\mathrm{SITO}^{73}$ la fidelidad a la Constitución no debería establecerse como límite a la libertad de cátedra de modo que la crítica a nuestra Norma Fundamental podrá hacerse siempre y cuando el contenido de la asignatura y la edad y el grado de madurez de los alumnos así lo per$\operatorname{mitan}^{74}$. Esto nos llevaría a la conclusión de que será esencialmente en el nivel universitario y en el campo de las ciencias sociales donde tal crítica pueda efectuarse: así por ejemplo la crítica podrá ser técnica o ideológica y, además, en algunos casos -siendo paradigmático el ejemplo de la asignatura de Derecho Constitucional- la crítica a la Constitución formará parte del contenido de la materia y por todo ello estará amparada en la libertad de cátedra.

Partiendo de lo señalado, vamos a plantearnos específicamente los posibles problemas que la condición funcionarial del docente puede implicar para articular su ejercicio de la libertad de cátedra. Hemos de partir del principio de que el deber de fidelidad a la Constitución supone uno de los límites derivados de los principios rectores de toda Administración pública y del estatuto de los funcionarios que la legislación sobre la función pública establece para todos ellos ${ }^{75}$. Por

72 Embid Irujo, A., Las libertades de la enseñanza, cit. en núm. 30, págs. 306

73 Expósito, E., La libertad de cátedra, cit. en núm. 21, pág. 218; en la misma línea, Rodríguez Coarasa, C., La libertad de enseñanza en España, cit. en núm. 9, pág. 232. Del mismo modo Salguero niega la existencia de este deber de fidelidad a la Constitución aunque admite que todos los docentes, funcionarios o no, han de respetar en su función los valores constitucionales. SALguero Salguero, M., Libertad de Cátedra y Derechos de los Centros Educativos, cit. en núm. 15, pág. 109 y ss.

${ }^{74}$ Como señala Díaz Revorio, refiriéndose ya al ámbito universitario, no existe ninguna obligación positiva por parte de estos docentes en relación con los valores constitucionales, "teniendo en cuenta la edad de los alumnos y su nivel de formación». Díaz Revorio, F. J., Los derechos fundamentales del ámbito educativo en el ordenamiento estatal y autonómico de Castilla-La Mancha, cit. en núm. 33, pág. 98.

75 En este sentido la Ley 7/2007, de 12 de abril, del Estatuto Básico del Empleado 
tanto si bien todos los ciudadanos y los poderes públicos están sujetos a la Constitución -por mandato expreso del artículo 9.1 de nuestra Norma Fundamental- y al resto del ordenamiento jurídico, los primeros tendrán una relación de sujeción pasiva, mientras que para los funcionarios se trata de una relación activa ${ }^{76}$.

A partir de aquí la cuestión a decidir es si merced a esta posición de sujeción activa se produce una especial obligación de lealtad o fidelidad del funcionario docente a la Constitución y en qué medida ello supone un límite, mayor o menor, a la libertad de cátedra. Responde a ello Expósıto considerando que, en el caso de los docentes funcionarios, no se puede predicar esa limitación teniendo en cuenta precisamente que la propia Norma Fundamental les reconoce su derecho a la libertad de cátedra. En contra de esta postura, LozANO ${ }^{77}$ destaca la especial posición de los docentes a quienes como funcionarios y por razones de la naturaleza del servicio público se les impone un mayor grado de exigencia en la fidelidad a la Constitución. De esta manera, con los docentes no universitarios se producirá un paradójico efecto derivado de la extensión a este colectivo del reconocimiento de la libertad de cátedra ya que «un derecho que surge para garantizar la libertad de expresión de los profesores respecto del resto de los funcionarios que no la tenían asegurada, supone hoy más una restricción que una garantía de esta libertad en el conjunto de la función pública» ${ }^{78}$.

\section{III.8. La libertad del estudio del alumno como límite a la libertad de cátedra}

De nuevo nos encontramos ante un límite controvertido doctrinalmente y en todo caso aplicable principalmente al ámbito universitario $^{79}$ en el que sí se podrían atisbar ciertas vías de reconocimiento

Público establece, en su artículo 95.2 a), que será falta muy grave: «El incumplimiento del deber de respeto a la Constitución y a los respectivos Estatutos de Autonomía de las Comunidades Autónomas y Ciudades de Ceuta y Melilla, en el ejercicio de la función pública».

${ }^{76}$ APARICIO Pérez, M. A., «El acatamiento de la Constitución, requisito de la condición plena del parlamentario (comentario a la Sentencia del Tribunal Constitucional de 18 de noviembre y 16 de diciembre de 1983)», Revista Jurídica de Cataluña, vol. 4, 1985, págs. 1031, 1040 y 1041.

77 Lozano Cutanda, B., La libertad de cátedra, cit. en núm. 37, pág. 219.

78 Ibidem.

${ }^{79}$ Entendemos que esta libertad de estudio resulta esencial y principalmente aplicable al ámbito universitario por diversas razones. En primer lugar, porque en la 
expreso. Al hacer referencia a este límite estaremos situando a los derechos de los alumnos como un límite lógico de la libertad de cátedra de los docentes. Pues bien, a partir del artículo 6.3.e) de la Ley Orgánica 8/1985, de 3 de julio, reguladora del Derecho a la Educación, por el que se reconoce a los alumnos el «derecho a que se respete su libertad de conciencia, sus convicciones religiosas y sus convicciones morales, de acuerdo con la Constitución ${ }^{80}$, algunos autores ${ }^{81}$ interpretan la existencia de un derecho a la objeción de conciencia de los alumnos, planteándose entonces el problema de cómo hacerlo compatible con la libertad de cátedra.

Resumidamente señalaremos que desde esta perspectiva doctrinal se defiende, en primer lugar, que el alumno «sólo podrá negarse al aprendizaje de contenidos no científicos de índole fuertemente religiosa y moral (...) pero no negarse al mero estudio, sino únicamente a la obligación de aceptar como propias determinadas concepciones ${ }^{82}$. En segundo lugar, se podría entender que ante los supuestos de grave confrontación debería permitirse al alumno el estudio de bibliografía alternativa y el asesoramiento de profesores afines a su ideología ${ }^{83}$.

Ley Orgánica de Educación 2/2006 no se habla expresamente de libertad de estudio como sí ocurre en el ámbito universitario con Ley Orgánica 6/2001, de 21 de diciembre, de Universidades. En segundo lugar, por la necesaria modulación de este derecho a la libertad de estudio en los niveles inferiores de la enseñanza en los que el alumno goza de menor capacidad crítica (con esta lógica, el propio artículo 6.1 de la Ley Orgánica 8/1985, de 3 de julio, reguladora del Derecho a la Educación afirma que: «Todos los alumnos tienen los mismos derechos y deberes, sin más distinciones que las derivadas de su edad y del nivel que estén cursando») y, dada su edad, está doblemente tutelado en su formación por docentes y profesores. No obstante, señaladas estas objeciones, no olvidamos aquí ejemplos reales en los que directa o indirectamente se ha presentado este derecho a la objeción de conciencia en ámbitos no universitarios, relacionándolo tácita o expresamente con la libertad de cátedra o la libertad de estudio como han sido los ya comentados recursos frente a la asignatura de Educación para la Ciudadanía.

${ }^{80}$ Como es lógico este artículo se ha reconocido en toda la normativa de desarrollo de la Ley Orgánica 8/1985, de 3 de julio, reguladora del Derecho a la Educación. Por ejemplo, en el caso del Principado de Asturias, el artículo 7.1 del Decreto 249/2007, de 26 de septiembre, regulador de los derechos y deberes del alumnado y normas de convivencia en los centros docentes no universitarios, establece que «los alumnos o alumnas tiene derecho a que se respete su libertad de conciencia, sus convicciones religiosas y sus convicciones morales, de acuerdo con la Constitución».

${ }^{81}$ Escobar Roca, G., La objeción de conciencia en la Constitución española, Centro de Estudios Constitucionales, Madrid, 1993, págs. 244 y ss.

${ }^{82}$ Lorenzo Vázouez, P., Libertad religiosa y enseñanza de la Constitución, cit. en núm. 19, pág. 227.

83 Ibidem, pág. 228. 


\section{III.9. El principio de neutralidad ideológica de la enseñanza pública no universitaria}

De acuerdo con el artículo primero de nuestra Constitución la libertad y el pluralismo son valores superiores del ordenamiento jurídico en nuestro Estado social y democrático de derecho. Ya en el ámbito de la enseñanza, de estos valores se deriva para el alumnado el derecho a recibir una educación acorde con sus convicciones religiosas y morales, derecho éste cuya titularidad, en el caso de los menores de edad -con imposibilidad material y moral de decidir por sí mismos la orientación ideológica en su proceso educativo- se atribuye a sus padres ${ }^{84}$. A partir de este planteamiento general, nuestra Carta Magna garantiza dos vías para que se aplique con plenitud este derecho: por una parte la del artículo 27.3 de la Constitución por el que «los poderes públicos garantizan el derecho que asiste a los padres para que sus hijos reciban la formación religiosa y moral que esté de acuerdo con sus propias convicciones» y, por otro lado, la vía del artículo 27.6 que reconoce la libertad de creación de centros docentes.

En el ámbito de la educación no universitaria, nuestro Alto Tribunal reconoció la vigencia y virtualidad de este principio de neutralidad, entendido como neutralidad-abstención, en la esencial Sentencia $5 / 1981^{85}$ y, por su parte el legislador lo plasmó en el artículo 18.1 de la Ley Orgánica 8/1985, de 3 de julio, reguladora del Derecho a la Educación según el cuál «todos los centros públicos desarrollarán sus actividades con sujeción a los principios constitucionales, garantía de neutralidad ideológica y respeto de las opciones religiosas y morales a que hace referencia el artículo 27.3 de la Constitución». De acuerdo con este marco jurídico, el principio de neutralidad supone esencialmente la proscripción de todo adoctrinamiento ideoló-

${ }^{84}$ Y ello porque, tal y como tempranamente estableció ya el Tribunal Europeo de Derechos Humanos en la Sentencia de 7 de diciembre de 1976, caso Kjeldsen, Busk Madsen y Pedersen, al asumir la responsabilidad sobre la educación de sus hijos es lógico que tengan derecho a que sus hijos reciban una formación acorde con sus convicciones.

85 «En un sistema jurídico político basado en el pluralismo, la libertad ideológica y religiosa de los individuos y la confesionalidad del Estado, todas las instituciones públicas y muy especialmente los centros docentes, han de ser, en efecto, ideológicamente neutrales. Esta neutralidad, que no impide la organización en los centros públicos de enseñanzas de seguimiento libre para hacer posible el derecho de los padres a elegir para sus hijos la formación religiosa y moral que esté de acuerdo con sus propias convicciones (artículo 27.3 Constitución), es una característica necesaria de cada uno de los puestos docentes integrados en el centro, y no el hipotético resultado de la casual coincidencia en el mismo centro y frente a los mismos alumnos, de profesores de distinta orientación ideológica (...)». FJ $9^{\circ}$, in fine. 
gico de los alumnos de lo que se derivará una doble autolimitación: que los profesores renuncien a exponer libremente sus ideas y opiniones y que el Estado renuncie, a su vez, a imponerles la enseñanza de una doctrina oficial. Por tanto el Estado respetará la libertad ideológica del profesor y éste respetará la del alumno aspirando así a un ámbito ideal de neutralidad ideológica «en el que nadie ve cuestionada su ideología, religión o creencia, pero en el que nadie puede tampoco predicarlas a los demás» ${ }^{86}$.

Resulta evidente que el respeto a este principio de neutralidad ideológica limita el ejercicio de la libertad de cátedra impidiendo así la libre expresión de las ideas o convicciones del docente. Entronca de esta manera con el contenido negativo uniforme de la libertad de cátedra y también con otros límites como son la exigencia de rigor científico y la prohibición del proselitismo o a la cláusula de especialidad de la protección de la juventud y la infancia recogida en el 20.4 de la Constitución. Ahora bien la incidencia de este principio de neutralidad ideológica será mayor cuanto menor sea el nivel educativo, reiterando de nuevo, que en los niveles superiores de la enseñanza no universitaria el alumnado tiene ya una cierta capacidad crítica que admitirá mayor libertad de sus docentes para expresar sus ideas o creencias ${ }^{87}$. Concluimos por tanto que la libertad de cátedra del profesor de la enseñanza pública no universitaria podría calificarse como de ejercicio imperfecto ${ }^{88}$, como lo es también la libertad de los padres de los alumnos, que se configura igualmente de manera negativa, como derecho a que sus hijos no sean adoctrinados en contra de su voluntad ${ }^{89}$. Y es que, acudiendo a las gráficas palabras de

${ }^{86}$ Lozano Cutanda, B., La libertad de cátedra, cit. en núm. 37, pág. 237.

87 Recordamos al respecto que la propia Ley Orgánica 2/2006, de Educación establece, en su artículo 2. k) entre los fines del sistema educativo, la preparación para el ejercicio de la ciudadanía y para la participación activa en la vida económica, social y cultural, con actitud crítica y responsable y con capacidad de adaptación a las situaciones cambiantes de la sociedad del conocimiento. Y referida a la etapa de Bachillerato se establece, en el artículo 33.b), entre los objetivos concretos, el consolidar una madurez personal y social que les permita actuar de forma responsable y autónoma y desarrollar su espíritu crítico.

${ }_{88}$ Lozano Cutanda, B., La libertad de cátedra, cit. en núm. 37, pág. 238.

89 Como señala Tomas y Valiente en el apartado 21 de su voto particular a la Sentencia 5/1981, refiriéndose al ejercicio del derecho del artículo 27.3 CE: «Los centros públicos permiten, pues, ejercer este derecho a todos los padres, aunque algunos de ellos puedan considerar que lo hacen de un modo imperfecto o menos satisfactorio que un centro privado en el que se impartiera una educación más homogénea ideológicamente. Por el contrario, los centros privados dotados de ideario educativo satisfarán plenamente el derecho del 27.3 de aquellos padres que se sientan identificados con ese ideario, pero obviamente no el de aquellos padres que lo rechacen por motivos también ideológicos». 
nuestro Tribunal Constitucional, en un centro público la libertad de cátedra estará limitada por la necesaria neutralidad de la enseñanza pública de modo que ésta nunca podrá ser «el hipotético resultado de la casual coincidencia en el mismo centro y frente a los mismos alumnos de profesores de distinta orientación ideológica cuyas enseñanzas se neutralicen recíprocamente ${ }^{90}$.

\section{III.10. El derecho a la objeción de conciencia a contenidos curriculares. Libertad de cátedra y contenido de las asignaturas}

Para algunos enfoques doctrinales minoritarios se pueden producirse lesiones en este derecho de los docentes aplicando el doble juego del derecho que asiste a los padres para que sus hijos reciban la formación religiosa y moral que esté de acuerdo con sus propias convicciones -artículo 27.3 de la Constitución- con el de otros límites de la libertad de cátedra como el deber de enseñar o la libertad de conciencia de los alumnos y el rigor científico. Desde este punto de vista estaríamos hablando no tanto de limitaciones a la libertad de cátedra sino que, por el contrario, se trataría de facultades derivadas del contenido negativo de la misma y el consiguiente derecho de resistencia ${ }^{91}$.

Con este enfoque, VEGA ${ }^{92}$ considera que de todas las posibles objeciones educativas ${ }^{93}$, aquellas objeciones fundamentadas en el contenido curricular y/o en los métodos pedagógicos son las que presentan una mayor incidencia en el contenido esencial de la libertad religiosa y de conciencia. Para ello se parte de la idea de que en el derecho a la educación, como derecho social de prestación, no cabe una instrucción orientada ideológicamente por el Estado, al estar además,

90 Salvador Martínez, M., «Los derechos de la educación», cit. en 23, pág. 404.

91 Recordamos al respecto lo que señala la Sentencia 5/81, de 13 de febrero, FJ 9 ${ }^{\circ}$, párrafo $4^{\circ}$ : «A resistir cualquier mandato de dar a su enseñanza una orientación ideológica determinada; es decir, cualquier orientación que implique un determinado enfoque de la realidad natural, histórica o social dentro de lo que el amplio marco de los principios constitucionales hace posible. Libertad de cátedra es, en ese sentido, noción incompatible con la existencia de una ciencia o una doctrina oficiales»

92 Vega Gutiérrez, A. M., "La objeción de conciencia en el ámbito educativo», en VVAA, Los derechos fundamentales en la educación, Madrid: CGPJ, 2008, págs. 281-2.

${ }^{93}$ Y se pueden distinguir diversos tipos: objeciones contra la enseñanza básica obligatoria como el absentismo escolar o la objeción a la propia escolarización o homeschooling; y objeciones contra la programación general diseñada por los poderes públicos, según el artículo $27.5 \mathrm{CE}$, entre las que se encontrará esta objeción a contenidos curriculares. 
la neutralidad incorporada al objeto básico de la educación. Fuera de esta frontera infranqueable cabrían una pluralidad de contenidos y diseños curriculares que, sin dejar de ser neutrales, pueden incidir en la libertad de conciencia de algunas minorías o personas. Es en estos casos en los que de facto se plantean los problemas para armonizar de manera equilibrada la doble dimensión, de libertad y social prestacional, del derecho a la educación.

Hasta el momento el criterio adoptado por los tribunales para resolver estos conflictos que pueden tener una incidencia indirecta en la libertad de cátedra parte de los principios establecidos por el Tribunal Europeo de los Derechos Humanos ${ }^{94}$. Así en el único caso de relieve planteado en relación con materias curriculares obligatorias, antes de que se produjera la polémica sobre la asignatura de Educación para la Ciudadanía, el Tribunal Superior de Justicia de Cantabria no reconoció la pretensión paterna de exención de una alumna de cursar y examinarse la materia escolar de ciencias naturales al entender que sus contenidos referidos a la sexualidad contradicen su derecho a que su hija reciba una formación religiosa y moral conforme a las propias convicciones ${ }^{95}$.

Posteriormente algunos padres han invocado su derecho a la objeción de conciencia frente a la obligación de que sus hijos cursen las asignaturas de Educación para la Ciudadanía ${ }^{96}$, argumentando para

94 Ante este problema el Tribunal Europeo de Derechos Humanos sostuvo ya tempranamente en la Sentencia de 7 de diciembre de 1976, el denominado caso Kjeldsen, Busk Madsen y Pedersen, un planteamiento general según el cuál el derecho de los padres a educar a sus hijos conforme a sus convicciones no les autoriza a oponerse a la integración de una determinada materia en el programa escolar, aunque se trate de informaciones o conocimientos que tengan directa o indirectamente, un carácter religioso o filosófico, porque de lo contrario sería inviable cualquier enseñanza institucionalizada.

95 Sentencia de la Sala de lo Contencioso-Administrativo del Tribunal Superior de Justicia de Cantabria, de 23 de marzo de 1998, en donde, en lo sustancial, se rechaza que el derecho invocado ampare la imposición de una discriminación positiva y la predeterminación del contenido del proyecto educativo de un Centro público en función de un ideario particular.

${ }^{96}$ Hay que tener en cuenta que aunque se denomina de manera genérica y coloquial a la materia "Educación para la Ciudadanía y los Derechos Humanos» como Educación para la Ciudadanía, en realidad se trata de un grupo de asignaturas que se imparten en dos etapas diferentes con alumnos de diferentes edades y capacidad crítica: en uno de los dos cursos del tercer ciclo de Primaria, es decir, a alumnos de entre 10 y 12 años; en uno de los tres primeros cursos de la ESO, esto es, a alumnos de entre 12 y 15 años; la asignatura "Educación ético-cívica», que se impartirá en $4^{\circ}$ de la ESO, esto es, a alumnos de entre 15 y 16 años; y, por último, la asignatura "Filosofía y ciudadanía», que se impartirá en un curso de Bachillerato, esto es, a alumnos de entre 16 y 18 años. 
ello el que algunos de sus contenidos implican una formación moral contraria a sus convicciones y a los derechos humanos. Ante estos planteamientos, el Tribunal Supremo, en su Sentencia del Pleno de la Sala Tercera de lo Contencioso-Administrativo, de 11 de febrero de 2009, no ha reconocido la pretensión de estos particulares fundamentando su pronunciamiento en diversas razones jurídicas y fácticas algunas de las cuáles guardan relación indirecta con la delimitación de la libertad de cátedra. En primer lugar, el Tribunal Supremo recuerda que la jurisprudencia constitucional española no ofrece base para afirmar la existencia de un derecho a la objeción de conciencia de alcance general, el cuál en todo caso, precisaría de una interpositio legislatoris. En segundo lugar, se niega a los padres la posesión de un derecho ilimitado a oponerse a la programación de la enseñanza por el Estado interpretando que el artículo 27.3 «permite pedir que se anulen las normas reguladoras de una asignatura obligatoria en tanto en cuanto invadan el derecho de los padres a decidir la enseñanza que deben recibir sus hijos en materia religiosa o moral; pero no permite pedir dispensas o exenciones ${ }^{97}$.

También se destaca la falta de adoctrinamiento en los fines y contenidos de esta asignatura ${ }^{98}$, si bien en este pronunciamiento se afirma que el hecho de que esta asignatura resulte ajustada a derecho y que por ello se considere válido el deber jurídico de cursarla, no autoriza a los docentes a inculcar o imponer, ni siquiera indirectamente, puntos de vista determinados sobre cuestiones morales controvertidas ${ }^{99}$. En todo caso nos encontramos con una polémica

97 Sentencia del Pleno de la Sala Tercera de lo Contencioso-Administrativo, de 11 de febrero de 2009, F.J. 7. Más adelante, se afirma que: «(...) hay que recordar que los apartados segundo y tercero del artículo 27 se limitan mutuamente: ciertamente, el Estado no puede llevar sus competencias educativas tan lejos que invada el derecho de los padres a decidir sobre la educación religiosa y moral de los hijos; pero, paralelamente, tampoco los padres pueden llevar este último derecho tan lejos que desvirtúe el deber del Estado de garantizar una educación en el respeto a los principios democráticos de convivencia y a los derechos y libertades fundamentales». F.J. 8.

98 «No advertimos, pues, en este punto el adoctrinamiento del que se nos habla, ya que el fin perseguido con la enseñanza de esta materia es que los alumnos conozcan, comprendan y respeten los valores en cuestión y sean capaces de comportarse en la vida pública con arreglo a las normas jurídicas que los expresan. No se busca en cambio, que los acepten en el fuero interno como única y exclusiva pauta a la que ajustar su conducta ni que renuncien a sus propias convicciones». Ibidem F.J. 12.

99 Ibidem, F.J. $15^{\circ}$. Por ello se afirma que estas cuestiones morales controvertidas «pertenecen al ámbito del libre debate en la sociedad civil, donde no se da la relación vertical profesor-alumno, y por supuesto al de las conciencias individuales. Todo ello implica que cuando deban abordarse problemas de esa índole al impartir la materia Educación para la Ciudadanía -o, llegado el caso, cualquier otra- es exigible la más exquisita objetividad y el más prudente distanciamiento». 
jurisprudencialmente no cerrada, habida cuenta de que en algunas sentencias posteriores a la del propio Pleno del Tribunal Supremo sí se ha reconocido el pretendido derecho a la objeción de conciencia a esta asignatura ${ }^{100}$.

Descrita la situación jurisprudencial de esta polémica, corresponde ahora acercarla a sus conexiones con la libertad de cátedra. Si bien es cierto que hasta el momento no se ha producido ningún pronunciamiento judicial fundamentado en el recurso de un docente que haya invocado su libertad de cátedra para no impartir esta asignatura ${ }^{101} \mathrm{o}$, incluso, un hipotético derecho a la objeción de conciencia ${ }^{102}$, ello no ha de impedir que en un plano teórico nos podamos

100 Nos referimos a las dos Sentencias de la Sección Tercera de Sala de lo Contencioso-Administrativo del Tribunal Superior de Justicia de Castilla y León, $\mathrm{n}^{\circ} 1.998$ y 1.999 , de 23 de septiembre de 2009. Con estas sentencias se anula una orden de la Consejería de Educación en la que se rechaza la objeción de conciencia solicitada por la madre de una alumna al apreciar «riesgo exorbitante, que los padres no vienen obligados jurídicamente a soportar ni a esperar se cristalice, de invasión, injerencia o inmisión en la esfera de privacidad que el artículo 27.3 CE». Además se reconoce «la intensa carga ética, moral e ideológica de la asignatura discutida, que emplea conceptos difusos e indeterminados» así como el «confesado propósito de reconstrucción, no de simple construcción, de valores en orden a la influencia en los comportamientos y actitudes, habilidades y destrezas de los menores (no conocimientos)».

101 En todo caso recordamos la Sentencia del Juzgado de lo Contencioso-Administrativo de Valencia de 23 de junio de 2009. En este supuesto sí se utilizaba la libertad de cátedra pero ante una particular metodología de impartición de esta asignatura. Se resolvía el recurso de un profesor de enseñanza secundaria contra la Orden de la Conselleria de Educación valenciana por la que se establece la impartición de la asignatura Educación para la Ciudadanía y los Derechos Humanos en inglés y con dos profesores en el aula. Con esta metodología y atribución docente se producía, en opinión del recurrente, una vulneración de su derecho a la libertad de cátedra. El juez considera que pese a la dificultad de la metodología impuesta por la Orden recurrida, la libertad de cátedra no está afectada en ningún modo, «sin obviar la falta de potestad del profesor de inglés para incidir en la libertad individual docente del profesor titular, debiendo seguir sus pautas y transmitiendo los conocimientos e ideas expuestos por él». El juez decide desestimar el recurso ya que «no puede identificarse el derecho a la libertad de cátedra como la potestad de su titular a autorregular íntegramente y por sí mismo la función docente y en modo alguno puede tenerse por violentado por el establecimiento por parte de la Conselleria de una específica metodología para la impartición de la docencia de la disciplina Educación para la Ciudadanía».

102 En este sentido debemos tener en cuenta los razonamientos de Ruiz Miguel al respecto de la existencia de un derecho a la objeción de conciencia reconocido con carácter amplio. En su opinión, el Tribunal Constitucional, «tras una compleja evolución, parece haber terminado reduciendo el alcance constitucional de la objeción de conciencia al ámbito de las obligaciones militares mencionadas en el artículo 30.2 de la Constitución. En este proceso de reducción de la objeción de conciencia constitucionalmente reconocida ha debido de pesar decisivamente la peculiar intratabilidad jurídica del reconocimiento expreso de algo semejante a un derecho genérico a tal for- 
plantear, al menos, si cabe esta posibilidad. ¿Resultaría plausible y justificable jurídicamente la invocación de que la libertad de cátedra de un docente sea afectada por asignaturas objeto de polémica por sus contenidos?. Por razones de concisión, brevedad y necesario ajuste al objetivo central del presente estudio, únicamente dejaremos apuntado aquí la existencia de minoritarias opiniones doctrinales para las que esta libertad de cátedra del docente sí se podría ver afectada por estos contenidos, los cuáles se erigirían, desde este enfoque, en una suerte de nuevo límite de este derecho. En esta línea señalamos la opinión de OTADUY GUERIN ${ }^{103}$ para quién la libertad de cátedra, en su vertiente de contenido negativo uniforme, capacitaría al docente a rechazar contenidos contrarios a sus convicciones. También avanza en estos planteamientos RUANo EsPINA para quién en los supuestos en los que entre en conflicto el deber de enseñar del profesor desde su puesto concreto y sus convicciones personales afectadas por una materia «que sea adoctrinadora, teñida de una orientación ideológica concreta (...) la negativa del profesor a impartir la Educación para la Ciudadanía, puede quedar suficientemente amparada por el ejercicio del derecho a la libertad de cátedra» ${ }^{104}$.

ma de objeción, incluso circunscrito en los límites que antes he propuesto o en otros más o menos similares. (...).Para que se mantenga como excepción a un deber generalmente cumplido es por lo que, precisamente, la objeción de conciencia nunca se suele configurar legalmente como un derecho realizable mediante su mera alegación. Si así fuera, presumiblemente, la objeción dejaría pronto de ser una excepción hasta transformarse de hecho -al igual que el deber general originario- en una simple libertad». Ruiz Miguel, A., "La objeción de conciencia a deberes cívicos», Revista Española de Derecho Constitucional, núm. 47, 1996, págs. 104 y 105. En línea similar, Escobar Roca, G., La objeción de conciencia en la Constitución española, cit. en núm 103, pág. 378 y ss.

${ }_{103}$ Otaduy Guerin, J., «Neutralidad ideológica del estado y del sistema educativo público», cit. en núm. 49, pág. 4. En su opinión el principio de neutralidad estatal en la enseñanza se puede ver atacado por dos vías. La primera, la del docente que como agente del Estado ejerce abusivamente la libertad de cátedra. En este caso considera que se trata de un acto individual, con efectos limitados y en la práctica poco frecuente. La segunda vía de ataque, siendo el ejemplo de la misma la polémica asignatura de Educación para la Ciudadanía, sería el intento de introducir por parte del Estado una orientación ideológica determinada en una materia del currículo obligatorio. Frente a esta situación se alzaría la libertad de cátedra en el sentido expuesto en el texto.

104 Ruano Espina parte de un derecho a la libertad de cátedra, aplicable a todos los docentes, universitarios o no, en todo tipo de centros (públicos, privados o concertados) y en todos los niveles educativos. En su opinión «este derecho faculta a los docentes, por una parte, a negarse y renunciar a cualquier forma de adoctrinamiento ideológico en el ejercicio de la docencia (dimensión negativa del derecho), pero también, por otra parte, a impartir los contenidos curriculares no sólo sin contrariar sus propias convicciones, sino de conformidad con su manera de entenderlos, o enjuiciarlos (dimensión positiva)». RUANO EsPINA, L., "Objeción de conciencia y educación 


\section{CONCLUSIONES}

Considerando el principal objetivo de este trabajo que no es otro que aportar argumentos jurídicos, jurisprudenciales y de práctica docente con los que arrojar luz sobre el grado de aplicación de la libertad de cátedra en el concreto ámbito de la enseñanza pública no universitaria, partimos de la base asentada por nuestro Alto Tribunal el cuál ha reconocido la libertad de cátedra a todos los docentes, sea cual fuere el nivel de enseñanza en que actúan y la relación que medie entre su docencia y la propia labor investigadora (STC 5/1981, FJ. 9). En esta línea se orienta el artículo 3 de la Ley Orgánica 8/1985, de 3 de julio, reguladora del Derecho a la Educación, en el que se sitúa a todos los profesores como titulares de esta libertad. Ahora bien, el contenido de la libertad de cátedra dependerá de las características del puesto docente desempeñado en función de dos factores: el nivel del puesto docente y la naturaleza privada o pública del centro.

Efectivamente, analizando indicadores como la transmisión de conocimientos, la valoración, la crítica, la investigación, la metodología y teniendo en cuenta quién es el sujeto receptor de los mensajes educativos, se puede comprobar la modulación del contenido de la libertad de cátedra en función de los niveles educativos. Pero conforme ascendemos en el itinerario educativo de las etapas no universitarias, situándonos dentro de ellas en las no obligatorias (Formación Profesional; Bachillerato; otras enseñanzas no universitarias como música, artes, idiomas) surgen argumentos de diversa naturaleza para ampliar el contenido y efectividad de la libertad de cátedra. En primer lugar, la existencia de factores como la mayoría de edad de los alumnos y su consiguiente madurez crítica y personal, la especialización de aprendizajes e itinerarios académicos o la cercanía al mercado de trabajo. Todos ellos podrían resumirse en la máxima: a mayor capacidad crítica del alumno, mayor libertad del profesor. En segundo lugar, el sentido aportado por la propia Constitución en su artículo 20.1.b, en el que se reconoce y protege, sin limitación en su titularidad, el derecho a «la producción y creación literaria, artística, científica y técnica». Es decir, se recoge por separado la libertad del profesor en su

para la ciudadanía». RUANO ESPINA, L., «Objeción de conciencia y educación para la ciudadanía», ponencia en la XXVIII Jornadas de Actualidad Canónica, Instituciones básicas, interacciones y zonas conflictivas de Derecho Canónico y Derecho Eclesiástico, Asociación Española de Canonistas, Madrid: Universidad Pontificia de Comillas, 2008, pág. 56. En la misma línea se sitúa MARTí SÁNCHEZ, J. M., «La Educación para la Ciudadanía. Ley Orgánica 2/2006, de Educación», Anuario de Derecho Eclesiástico del Estado, XXIII, 2007, pág. 247. 
ejercicio docente -libertad de cátedra- de la libertad de investigación. En tercer lugar, la normativa de base del sistema educativo no universitario, la Ley Orgánica 2/2006, de 3 de mayo, de Educación, que recoge entre sus principios el fomento y la promoción de la investigación, la experimentación y la innovación educativa (preámbulo y artículo 1); que defiende el reconocimiento de la labor didáctica o de investigación de profesores y centros (artículo 90) y que, entre las funciones del profesorado de estas etapas no universitarias, sitúa «la investigación, la experimentación y la mejora continua de los procesos de enseñanza correspondientes» (artículo 91.1). Además de todo ello, el Juez de la Constitución ha reconocido implícitamente estas funciones de investigación y estudio en los niveles no universitarios al afirmar que la libertad de cátedra presupone y precisa, no obstante, de una organización de la docencia y de la investigación que la haga posible y la garantice (STC 217/1992, de 1 de diciembre, FJ. $2^{\circ}$ ). Más claramente aún, nuestro Tribunal Constitucional reconoce que la amplitud de esta libertad en las etapas no universitarias es muy variable, ya que en ellas se comprenden desde los más elementales niveles de enseñanza, hasta los cursos de Bachillerato más cercanos ya a la enseñanza universitaria, tanto porque en parte sirven de preparación para ella, como porque con frecuencia los alumnos de ese Bachillerato han superado el tope constitucional de la mayoría de edad (STC 5/81, FJ. 13).

Por otro lado, en cuanto a los límites específicos de este derecho, el profesor ha de enseñar desde su puesto docente y no puede enseñar lo que «mejor le parezca» sino que «debe transmitir la materia objeto de su enseñanza» a partir de lo previsto en la programación de su asignatura. Y es cierto que en la enseñanza no universitaria esta programación estará delimitada a través de sucesivos círculos concéntricos que parecen constreñir hasta la extenuación la el campo de juego práctico de la libertad de cátedra: la normativa estatal que fija las enseñanzas mínimas, la normativa autonómica que desarrolla el currículo estatal, el propio desarrollo curricular hecho en cada centro educativo y finalmente, la supervisión-coordinación de los Departamentos didácticos respecto a la programación de cada docente. Sin embargo, la propia la Ley Orgánica 2/2006, de 3 de mayo, de Educación, aporta argumentos para defender la mayor cercanía, que no asimilación, del docente no universitario al ámbito universitario. Así por ejemplo establece la autonomía pedagógica y de gestión de los centros (artículo 120) o defiende los modelos abiertos de programación docente (artículo 121) con los que se logre atender a las distintas necesidades de los alumnos y del profesorado. 
Por último en cuanto al límite específico del principio de neutralidad ideológica de la enseñanza pública no universitaria, entendido como neutralidad-abstención, éste supone esencialmente la proscripción de todo adoctrinamiento ideológico de los alumnos. Evidentemente su incidencia será mayor cuanto menor sea el nivel educativo lo cuál nos lleva a finalizar asentando un matiz esencial en el que se apoya el presente estudio: en el caso de las etapas no obligatorias la mayor capacidad crítica y madurez del alumnado abrirá paso a una relativa mayor libertad del docente para expresar una diversidad de ideas y creencias. Ese parece ser además el espíritu del legislador cuando entre los fines del sistema educativo sitúa el potenciar en los alumnos una actitud crítica, su responsabilidad, su adaptación al cambió y consolidar su madurez personal y social. 